\title{
A State-of-the-Art Review on Biowaste Derived Chitosan Biomaterials for Biosorption of Organic Dyes: Parameter Studies, Kinetics, Isotherms and Thermodynamics
}

\author{
Yean Ling Pang ${ }^{1,2, * \mathbb{D}}$, Jia Hui Tan ${ }^{1}$, Steven Lim ${ }^{1,2} \mathbb{D}$ and Woon Chan Chong ${ }^{1,2} \mathbb{D}$ \\ 1 Department of Chemical Engineering, Lee Kong Chian Faculty of Engineering and Science, \\ Universiti Tunku Abdul Rahman, Bandar Sungai Long 43000, Malaysia; jiahui998@1utar.my (J.H.T.); \\ stevenlim@utar.edu.my (S.L.); chongwchan@utar.edu.my (W.C.C.) \\ 2 Centre for Photonics and Advanced Materials Research, Universiti Tunku Abdul Rahman, \\ Bandar Sungai Long 43000, Malaysia \\ * Correspondence: pangyl@utar.edu.my or pangyeanling@hotmail.com; Tel.: +60-3-9086-0288
}

check for updates

Citation: Pang, Y.L.; Tan, J.H.; Lim, S.; Chong, W.C. A State-of-the-Art Review on Biowaste Derived

Chitosan Biomaterials for Biosorption of Organic Dyes: Parameter Studies, Kinetics, Isotherms and Thermodynamics. Polymers 2021, 13, 3009. https://doi.org/10.3390/ polym13173009

Academic Editor: Min-Lang Tsai

Received: 10 August 2021

Accepted: 25 August 2021

Published: 6 September 2021

Publisher's Note: MDPI stays neutral with regard to jurisdictional claims in published maps and institutional affiliations.

Copyright: (c) 2021 by the authors. Licensee MDPI, Basel, Switzerland. This article is an open access article distributed under the terms and conditions of the Creative Commons Attribution (CC BY) license (https:// creativecommons.org/licenses/by/ $4.0 /)$.

\begin{abstract}
Chitosan is a second-most abundant biopolymer on earth after cellulose. Its unique properties have recently received particular attention from researchers to be used as a potential biosorbent for the removal of organic dyes. However, pure chitosan has some limitations that exhibit lower biosorption capacity, surface area and thermal stability than chitosan composites. The reinforcement materials used for the synthesis of chitosan composites were carbon-based materials, metal oxides and other biopolymers. This paper reviews the effects of several factors such as $\mathrm{pH}$, biosorbent dosage, initial dye concentration, contact time and temperature when utilizing chitosanbased materials as biosorbent for removing of organic dyes from contaminated water. The behaviour of the biosorption process for various chitosan composites was compared and analysed through the kinetic models, isotherm models and thermodynamic parameters. The findings revealed that pseudosecond-order (PSO) and Langmuir isotherm models were best suited for describing most of the biosorption processes or organic dyes. This indicated that monolayer chemisorption of organic dyes occurred on the surface of chitosan composites. Most of the biosorption processes were endothermic, feasible and spontaneous at the low temperature range between $288 \mathrm{~K}$ and $320 \mathrm{~K}$. Therefore, chitosan composites were proven to be a promising biosorbent for the removal of organic dyes.
\end{abstract}

Keywords: chitosan composites; parameter studies; kinetics; isotherms; thermodynamics

\section{Introduction}

Water is an essential and valuable component for sustaining the life of all living organisms and developing a sustainable ecosystem. However, water pollution has now become one of the most critical challenges facing many countries in accordance with the growth of urbanisation and socio-economic development. In Malaysia, approximately 97\% of the raw water supply for domestic, agricultural and industrial activities comes from rivers [1]. The increased number of slightly polluted and polluted rivers was mainly due to uncontrolled usage of various chemicals and improper discharge of effluents from the household and industrial sector into the river without adequate treatment [2]. Several studies have reported that the most common pollutants present in industrial wastewater are heavy metals, organic compounds and inorganic compounds. Textile dyes are among the major contributors to water pollution [3].

In the textile industry, dyes are organic compounds mainly used to provide colour and alter the crystal structure of the coloured substance [4]. However, the washing, dyeing, and finishing of textiles require high water consumption, which eventually generate a high discharge rate of wastewater containing organic dyes. Approximately $100-300 \mathrm{~m}^{3}$ of water are utilised to generate one tonne of textile [5]. The amount of dye in the effluent is closely 
linked to the fixation rates of the various dyes and fibres. Table 1 shows the degree of fixation and the percentage of loss in the effluent for various types of dyes. During the dyeing and finishing processes, no single dye has a $100 \%$ degree of fibre fixation [6]. As a result, a high number of dyes will end up in the water bodies, resulting in highly coloured effluent due to their incomplete degree of fixation and exhaustion. The high colour intensity of dyes prevents the light penetration into the river and reduces the dissolved oxygen, thereby severely affecting the aquatic diversity. The dyes can persist in the environment due to the high stability and low biodegradability of dyes. If long term consumption of drinking water contains organic dyes, they can bioaccumulate in the body and may induce cancer and tumours in humans and animals [7].

Table 1. Degree of fixation and percentage loss in effluent for various types of dyes [6].

\begin{tabular}{cccc}
\hline Dyes & Fibre Type & Loss in Effluent (\%) & Degree of Fixation (\%) \\
\hline Acid & Polyamide & $5-20$ & $80-95$ \\
Disperse & Polyester & $0-10$ & $90-100$ \\
Basic & Acrylic & $0-5$ & $95-100$ \\
Direct & Cellulose & $5-30$ & $70-95$ \\
Reactive & Cellulose & $10-50$ & $50-90$ \\
\hline
\end{tabular}

Therefore, the adsorption process is widely employed to remove non-biodegradable organic dyes [8]. Synthetic polymer is an effective adsorbent to remove dyes from wastewater. However, it is restricted by its costly supply chain, which can increase the capital cost of wastewater treatment. It is also non-biodegradable, which might lead to environmental problems related to its waste disposal [9]. In light of this, many researchers have focused on the evaluation of inexpensive and environmentally friendly alternative sorbents. Food wastes are renewable and inexpensive biopolymers that can be used for the production of biosorbents. According to the Food and Agriculture Organization of the United Nations, about 1.3 billion tonnes of food is lost or wasted annually [10]. Inefficient food waste management may contribute to some negative environmental issues such as infectious diseases, land and water pollution. Hence, the environmentally friendly approach is introduced to recycle these food wastes as secondary useful materials.

Food wastes are considered biopolymers that are rich in carbohydrates, lipids and proteins. The investigations on the recovery of chitosan from food waste especially marine food waste are deemed interesting due to the renewable attractive properties. According to the current research, the extraction of chitin and chitosan are commonly carried out by chemical or biological methods. The extraction process of chitin involves demineralization and deproteinization, followed by the deacetylation to convert chitin to chitosan by removal of acetyl group [11]. Knidri et al. [11] and Sivanesan et al. [12] had reviewed those extraction chitin and chitosan processes in details recently. Among the biopolymers, chitosan has been reported in the literature as a promising biosorbent for the removal of dyes $[13,14]$. It consists of carboxyl $(-\mathrm{COOH})$, hydroxyl $(-\mathrm{OH})$, amine $\left(-\mathrm{NH}_{2}\right)$ and amide $\left(-\mathrm{NHCOCH}_{3}\right)$ functional groups on its surface, which are responsible for the uptake of organic dyes through intermolecular interaction, hydrogen bonding and electrostatic attraction. However, pure chitosan has some limitations such as low adsorption capacity, low regenerative and poor mechanical strength, thereby limiting its potential applications. Hence, a chemical or physical modification of chitosan can be carried out by introducing the reinforcement material in the chitosan matrix to synthesise chitosan composite. In this study, various chitosan composites were studied to analyse their biosorption behaviours to remove organic dyes. The performance of chitosan composites for the biosorption of organic dyes were investigated through various parameter studies such as solution $\mathrm{pH}$, biosorbent dosage, initial dye concentration, contact time and solution temperature. This paper also reviewed the research state of the art of biosorption isotherms, kinetics and thermodynamics. 


\section{Biopolymers}

Biopolymers can be described as natural polymers synthesised by living organisms through naturally synthesised enzymes and catalysed chain growth polymerisation in their growth cycle of biological cells [15]. Many materials such as microorganisms, plants or trees that are commonly derived from biological sources can be described by the term "biopolymers". Materials chemically synthesised from biological raw materials such as starch, sugar, fat, resin, protein and vegetable oil can also be called biopolymers [16]. Biopolymers are mainly made up of a long chain of repeating monomer units that are covalently bonded to form larger molecules. There are three types of biopolymers: polysaccharides, polypeptides, and polynucleotides with the monomer units of sugars, amino acids and nucleotides, respectively.

Food wastes are also one of the primary sources of biopolymers. These food wastes are considered as a valuable renewable resource as they contain high-value components such as polysaccharides, proteins, and lipids. They can be converted into a variety of valuable products such as biochemical products and biofuels. Nowadays, biopolymers have been widely used in various sectors and have gradually replaced $30-90 \%$ of petrochemical polymers [17]. The unique properties of biodegradability, biocompatibility and renewability of biopolymers have attracted worldwide attention to be used as petrochemical polymers [18]. Among these biopolymers, polysaccharides such as chitosan, cellulose, and lignin have received particular attention for environmental application [19]. Polysaccharides are produced based on a renewable basis and represent the largest group of polymers currently produced in the world. In fact, more than 150 million tonnes of polysaccharides are produced annually, as compared to about 140 million tonnes of synthetic polymers [20]. Polysaccharides are polymers of amino sugars or glucose bonded by acetic bonds. It is well known that polysaccharides are biodegradable, available in abundance and have the ability to associate with various types of molecules through physical and chemical interactions [21].

Recent studies have explored the application of food waste derived biochemical components extracted from lignocellulosic substrates such as succinic acid and 2, 3butanediol as precursors for the production of biopolymers $[17,22]$. Biopolymers also can be used as natural coagulants and flocculants in the wastewater treatment to remove non-biodegradable and highly stable water pollutants such as organic dyes, pharmaceutical compounds and heavy metal ions [23]. These biopolymers are also widely used as biosorbents in the wastewater treatment plant because of their particular structures and physicochemical characteristics. They do not produce toxic by-products during the chemical treatment process [24]. In addition, biopolymers consist of several functional groups in their chemical structure, such as $-\mathrm{OH},-\mathrm{NH}_{2}$, and $-\mathrm{COOH}$ groups in their polymer chain. Hence, biopolymers have high reactivity and excellent selectivity towards aromatic compounds and metal ions. They are able to interact with organic compounds through chemical or physical sorption. More specifically, adsorption on polysaccharide derivatives can be considered as a cost-effective method to separate and remove contaminants from the water bodies. It is also an environmentally friendly method to preserve the environment. Besides, the increasing number of publications on the adsorption of toxic compounds by these biopolymers indicate a recent concern in the development of new adsorbent polysaccharides-containing materials [25].

In this study, the biopolymers are classified, and the types of biopolymers are described in the following sections. The biopolymers are then modified and used as biosorbents based on their adsorption capacity.

\subsection{Classification of Biopolymers}

The classification of biopolymers can be made based on the type of monomers, biodegradability, raw materials and backbones, as shown in Figure 1 [26]. Firstly, biopolymers can be categorised into two main groups, which are biodegradable and nonbiodegradable biopolymers. They are then alternatively categorised according to their 
origin, either being bio-based or non-bio-base biopolymers. Next, the biopolymer can also be classified based on their polymer backbone, including polyesters, polysaccharides, polycarbonates, polyamides and vinyl polymers. The three types of biopolymers can be further distinguished into polysaccharides, polypeptides and polynucleotides, depending on the type of monomers.
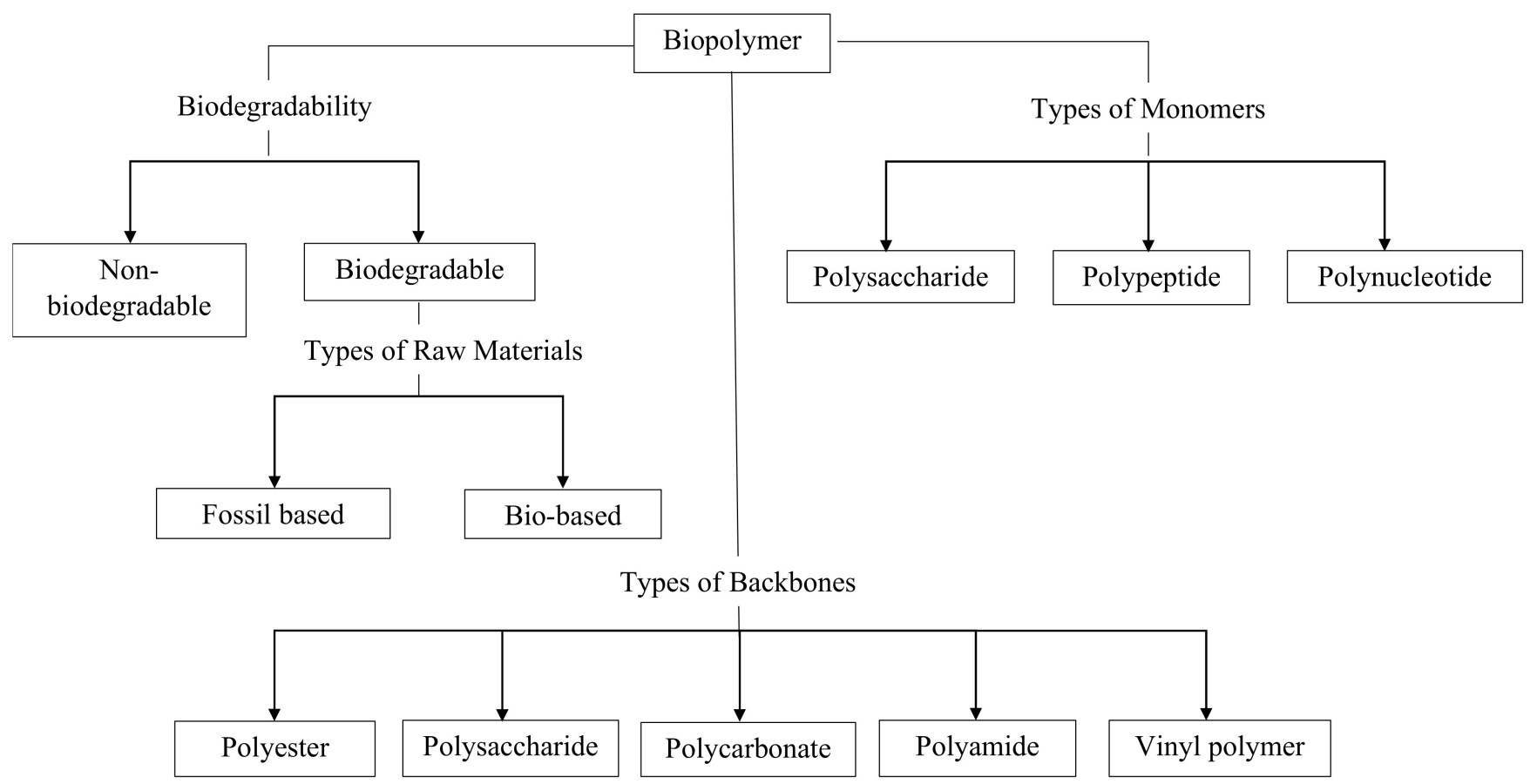

Figure 1. Classification of biopolymers based on the type of monomers, biodegradability, raw materials, and backbones [26]. Reproduced with permission from Elsevier Science Ltd.

Besides, the biopolymers can be further categorised based on the types of raw materials and their biodegradability. There are three categories of biopolymers: biodegradable bio-based biopolymers, non-biodegradable bio-based biopolymers and biodegradable fossil-based biopolymers.

\subsection{Types of Biopolymers}

Among the biopolymers, cellulose and chitosan are the first and second most abundant biopolymers in the world that have been successfully employed for wastewater treatment. Cellulose is a structural polysaccharide made up of repeating $\beta$-D-glucose units arranged in a linear chain and linked by $\beta(1 \rightarrow 4)$ glycosidic bonds through the condensation process [27]. Figure 2a illustrates the chemical structure of cellulose. The glycosidic bonds between $\beta$-D-glucose units make the structure of cellulose highly crystalline and stronger [23]. Approximately $33 \%$ of the plants are made up of cellulose. Citrus peels, wheat straw, rice and woody parts of vegetables are the richest cellulose source [28].

Chitin and chitosan are two promising biopolymers derived mainly from the exoskeleton of invertebrate animals and the cell walls of fungi. Chitin is a natural polysaccharide consist of a linear chain of 2-acetamido-2-deoxy-D-glucose joined by $\beta(1 \rightarrow 4)$ glycosidic bonds. Chitin is commonly obtained from commercial and marine sources such as crab shells, lobster shells, shrimp shells, oysters, squids, crawfish, cuttlefish and fungi [29]. Chitin is dumped as a waste product from the seafood industry and approximately $1 \times 10^{13} \mathrm{~kg}$ of chitin is produced annually. Moreover, approximately $8 \times 10^{4}$ tonnes of chitin are synthesised based on marine by-products [30].

Chitosan is the second most abundant biopolymer that is produced from chitin through the alkaline deacetylation process. Chitin deacetylation is a process that involves the reaction of chitin with $40 \%-50 \%$ sodium hydroxide solution to hydrolyse $-\mathrm{NHCOCH}_{3}$ 
groups into $-\mathrm{NH}_{2}$ groups. However, the degree of deacetylation can only achieve up to $98 \%$ because complete deacetylation is difficult to achieve due to the heterogeneous process. Thus, chitosan is considered a partial deacetylated form of chitin [31]. Generally, chitosan is formed from the units of D-glucosamine and a small amount of N-acetyl-D-glucosamine residue that joined by $\beta(1 \rightarrow 4)$ glycosidic bond [32]. Each glucosamine unit consists of a free amino group, and this group can take on a positive charge which allows chitosan to be used as a coagulant agent and adsorbent for the removal of organic compounds. Its coagulation effect is more effective than mineral coagulants such as aluminium sulphate, polyethene imide and polyacrylamide in the removal of various pollutants from the aqueous solution [33].

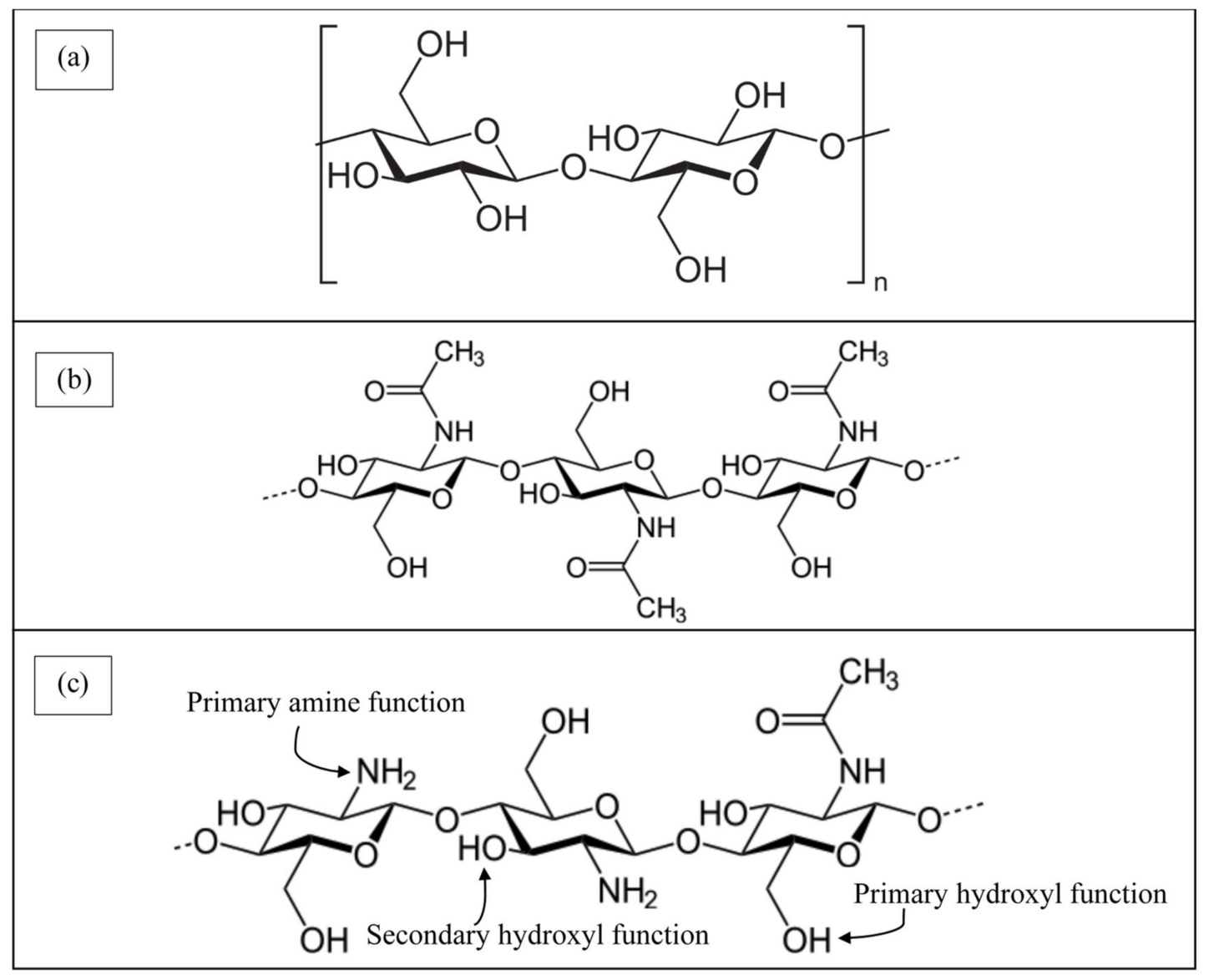

Figure 2. Chemical structures of (a) cellulose, (b) chitin and (c) chitosan.

Figure $2 b, c$ show the respective chemical structures of chitin and chitosan [27]. The chemical structure of chitosan is similar to chitin and cellulose, except the present of $-\mathrm{NH}_{2}$ groups in the chitosan structure. Nevertheless, the solubility of chitosan in the aqueous acid medium is higher than its precursor polymer (chitin) and cellulose, owing to the presence of $-\mathrm{NH}_{2}$ groups and $-\mathrm{OH}$ groups that are responsible for the adsorption process. Chitin is not suitable when used as a biosorbent for the adsorption of organic dyes as compared to chitosan due to its low solubility and low dispersion in water and other solvents. On the contrary, chitosan is soluble in soluble in most aqueous acid solutions such as acetic, citric, formic and lactic acids that are below its $\mathrm{pKa}(\mathrm{pH}=6.5)$ [11]. In order to improve the adsorption capacity of chitin for the removal of methylene blue dyes, Cao et al. [34] modified the chitin using a chemical process through protonation, carboxylation and grafting.

Chitosan has a long polymer chain and good polycation, aggregation and precipitation properties under neutral or alkaline $\mathrm{pH}$ conditions. It is biodegradable, biocompatible, non- 
toxic and inexpensive. The respective properties can promote the contact between polymer and organic pollutants. Chitosan can be used as coagulants and flocculants to remove the negatively charged colloidal organic and inorganic pollutants from water due to its high cationic charge density [35]. With their regenerative ability and environmentally friendly properties, they are ideally used in the adsorption process. Many research studies have been carried out to investigate the adsorption capacity of chitosan and its composites to remove organic pollutants from wastewater. The application of chitosan in water treatment such as organic dyes removal, heavy metals removal and oil treatment of aqueous emulsion were investigated $[14,29,36]$.

\subsection{Modification of Chitosan}

Among the biopolymers listed previously, chitosan was selected for further discussion in the following sections as it could be used as a potential biosorbent to remove organic dyes. However, pure chitosan was reported to have poor physicochemical properties in terms of morphological properties, surface area, functional groups and thermal stability, thereby reducing the biosorption capacity [37]. Therefore, chitosan was modified using chemical or physical methods to overcome its limitations and improve the performance of chitosan. There are several chitosan modification methods to improve the performance of chitosan on the adsorption efficiency, which are crosslinking, grafting and blending with other materials [38].

The grafting method is commonly used to promote the formation of chemical bonds between different types of polymers without mixing with other materials. This method can improve the physicochemical properties of chitosan by introducing additional functional groups such as $-\mathrm{NH}_{2},-\mathrm{NHCOCH}_{3},-\mathrm{COOH}$ or thiol into crosslinked chitosan [39]. Besides, polymer grafting also can improve the polymerisation degree of biopolymer, polydispersity of main chain and side chains, graft density, graft distribution or graft uniformity [40]. In general, polymer grafting can be prepared using three methods as shown in Figure 3 [41]. In details, the "grafting to" strategy involves attaching a pre-synthesised polymer onto the surface or backbone of the polymer. The "grafting from" strategy is based on the attachment of the initiator to a surface/polymer chain end followed by the growing of polymer chain. Finally, the "grafting through" strategy involves the polymerisation of a macromonomer.

Kyzas et al. [42] grafted chitosan with polyacrylamide and also with polyacrylic acid to improve the adsorption capacity of chitosan. Grafting of functional groups such as $-\mathrm{COOH}$, $-\mathrm{OH}$, sulphate, phosphate and $-\mathrm{NH}_{2}$ groups onto the biosorbent surface could increase the number of active sites of chitosan for the removal of organic dyes. For example, the surface of biosorbent was protonated by grafting $-\mathrm{NHCOCH}_{3}$ functional groups on the chitosan surface. As a result, this could improve the adsorption capacity of chitosan towards the negatively charged organic compounds. Besides, grafting of - $\mathrm{COOH}$ groups onto the surface of chitosan would result in more negative charges on the chitosan surface. Thus, this leads to the high adsorption capacity of chitosan towards cationic organic pollutants due to the strong interaction between cationic dyes and - $\mathrm{COOH}$ functional groups.

Moreover, crosslinking is one of the effective approaches to modify polymer microstructures via chemical or physical methods. However, excessive crosslinking will reduce the mechanical stability of polymers and therefore crosslinking must be performed in an appropriate and controlled manner [43]. Crosslinking reactions are commonly employed to prevent chitosan from dissolving in acidic media. At lower $\mathrm{pH}$, chitosan will be dissolved in an acidic medium and lose its ability to bind with adsorbates, subsequently restricting its applications in wastewater treatment. Therefore, crosslinking reagents containing multifunctional groups such as aldehydes, anhydrides and epoxides will be used to react with the functional groups on the surface of chitosan [44]. The common crosslinkers used include glutaraldehyde, epichlorohydrin, glyoxal formaldehyde, ethylene glycol diglycidyl ether and sodium tripolyphosphate [45]. 


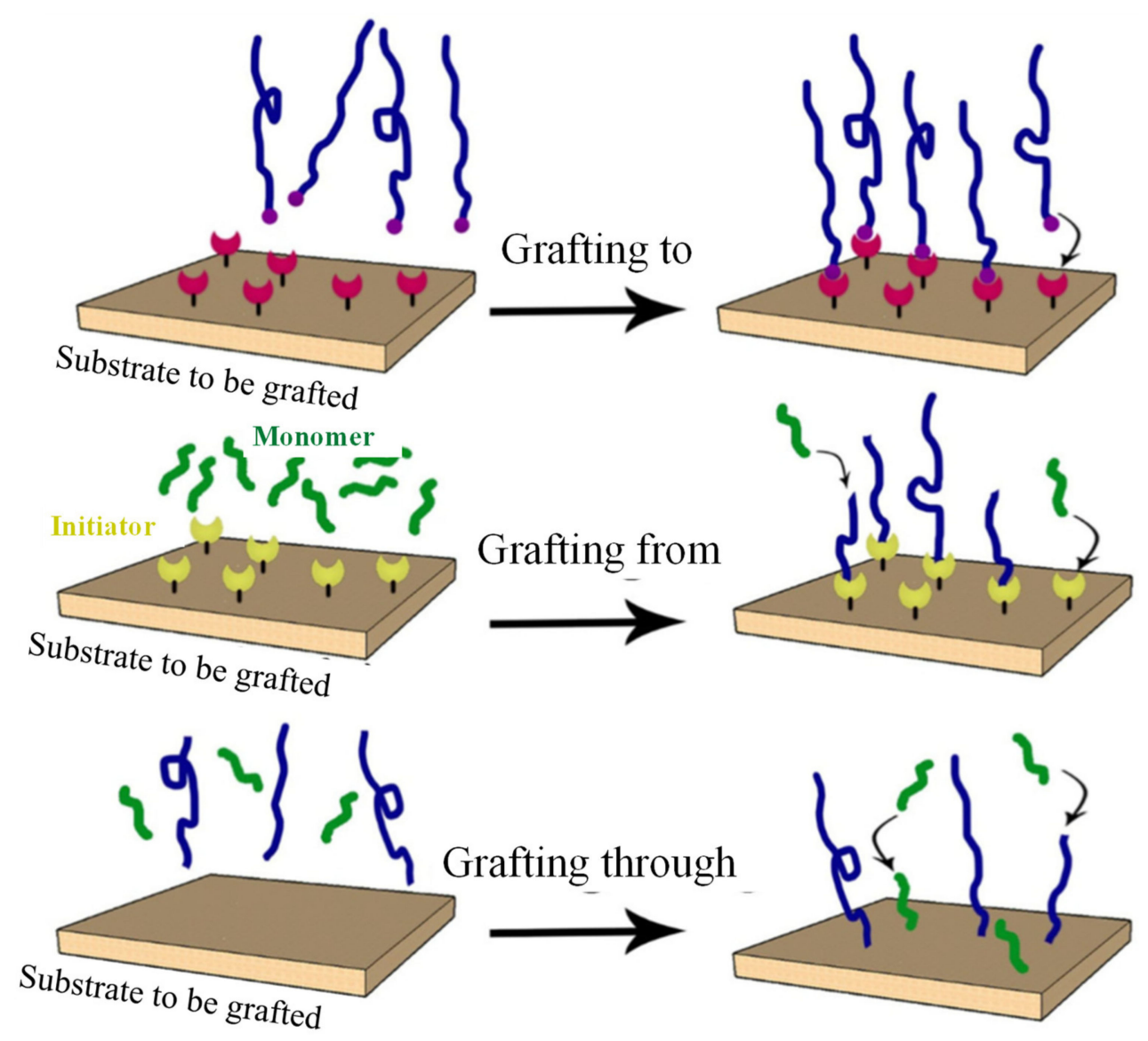

Figure 3. Polymer grafting methods [41]. Reproduced with permission from Elsevier Science Ltd.

Next, polymer blending is an economical and simple physical method of combining two or more materials, with or without any chemical bonds between their chains to develop a new material called polymer composite. However, it is provided that the concentration of polymer component in the blends should be above $2 \%$. Polymer blending with other materials is widely used to improve the mechanical properties of biopolymers due to their recyclability and biodegradability [46]. The components involved in the blending usually will have different physicochemical properties with each other. Therefore, blending also helps to overcome the shortage of reaction sites in the adsorption membrane structures of biopolymers. For example, Anitha, Kumar and Kumar [47] employed the polymer blending method to synthesise chitosan/polyvinyl alcohol (PVA) for the removal of Direct Red 80 dyes. Based on the results, chitosan/PVA could remove up to $89 \%$ of Direct Red 80 dyes, while pure chitosan only could remove $54 \%$ of dyes. The results indicated that blending PVA with chitosan could significantly improve the removal efficiency of dyes.

\section{Chitosan Composites}

Chitosan is a renewable, eco-friendly and biodegradable material that can be used as an alternative material for synthetic petroleum-based polymers. The use of biopolymers alone may be ineffective in removing the organic compounds from water. Its low mechanical strength, tensile strength, permeability and thermal stability had restrict its wide application [48]. Therefore, the best way to improve the properties such as increase stability of chitosan and its performance is to introduce reinforcement materials within the micro-regime or nano-regime [49].

Chitosan composites are biopolymer-based materials made up of two or more different substances that combine together to produce a new material with better performance than a single constituent material. These composite materials consist of two main phases: the matrix phase with low modulus and high elasticity, and the reinforcement phase with 
higher loading capacity [50]. A suitable biopolymer composite should be inexpensive, available in abundant, efficient, eco-friendly, biocompatible and reusable [51]. Typically, chitosan composites can be synthesised through crosslinking reaction between the positively charged group of chitosan and negatively charged crosslinking agent in the ionic gelation process.

\subsection{Chitosan/Zeolite}

Zeolite mainly contains aluminate and silicate with three-dimensional framework structures. It can be employed to remove organic pollutants due to its excellent adsorption properties with outstanding ion exchange and modification capabilities [52]. Natural zeolite is an abundant, environmentally friendly, inexpensive, chemically and mechanically stable hydrated alumina silicate material that can be used to form composites with chitosan. Xie et al. [53] have employed chitosan/zeolite composites to remove cationic, anionic and organic pollutants from aqueous solution with $31.6 \mathrm{mg} / \mathrm{g}$ adsorption capacity. Furthermore, Dehghani et al. [37] conducted an experimental study for the removal of methylene blue dye using pure chitosan and chitosan/zeolite composite. The results indicated that the dye removal efficiency using chitosan/zeolite was higher than pure chitosan. It was reported that $84.85 \%$ of the methylene blue was removed by the chitosan/zeolite composite with a maximum adsorption capacity of $24.5 \mathrm{mg} / \mathrm{g}$.

The chitosan/zeolite composite was synthesised through the bridging mechanisms and the formation of hydrogen bonds between the surface functional groups of chitosan with the - $\mathrm{OH}$, silano and aluminol groups of zeolite [52]. Based on the scanning electron microscopy (SEM) images obtained by Metin, Çiftçi and Alver [54], it was observed that pure chitosan had a lower specific surface area with a flake-like and smooth surface structure. However, the SEM image of chitosan/zeolite composite demonstrated a heterogeneous, irregular and rough surface as compared to pure chitosan. Besides, chitosan/zeolite possessed better thermal stability and experienced lower weight loss than pure chitosan during the thermal degradation process [55]. Therefore, the dye removal efficiency and thermal stability of chitosan were improved by immobilising zeolite in the chitosan matrix.

\subsection{Chitosan/Carbon-Based Materials}

Carbon-based materials such as multiwalled carbon nanotubes (MWCNTs) and graphene oxide are attractive adsorbents for water treatment. The adsorption capacity can be improved by introducing MWCNTs into the chitosan matrix. This is because MWCNTs have high surface areas, functionalisation capability with different surface functional groups and controllable size distribution. It was reported that chitosan/MWCNTs composite had higher thermal and mechanical strength as compared to pure biopolymer [56].

Salam, Makki and Abdelaal [57] added MWCNTs with average diameters of 60 to $100 \mathrm{~nm}$ in the chitosan matrix to synthesise a chitosan/MWCNTs composite. The MWCNTs were well dispersed on the surface of chitosan. Based on the SEM images, the membrane showed a porous structure morphology and sponge-like structure. Besides, TGA analysis showed that the thermal stability of chitosan/MWCNTs composite was higher than raw chitosan. The surface area of the MWCNTs was increased from 82.4 to $135.1 \mathrm{~m}^{2} / \mathrm{g}$ after the modification with chitosan. The excellent dispersion of MWCNTs in a chitosan matrix decreased the tangling and agglomeration of MWCNTs and greatly improved the adsorbent surface area.

Besides, graphene oxide has become a promising adsorbent material in wastewater treatment due to its excellent properties such as high surface areas and chemical stability. Graphene oxide consists of many functional groups, including $-\mathrm{COOH},-\mathrm{OH}$, diol, epoxy, and ketone groups. These functional groups cause graphene oxide to have higher hydrophilic and able to compatible with other biopolymers [58]. The - $\mathrm{COOH}$ group of graphene oxide can react with the $-\mathrm{NH}_{2}$ group of chitosan to form chitosan/graphene oxide composites. Huyen et al. [59] prepared chitosan/graphene oxide composites by lyophilisation for the removal of methylene blue. The results showed that the chitosan/graphene 
composites were found to be a suitable adsorbent for methylene blue with a maximum adsorption capacity of $662.25 \mathrm{mg} / \mathrm{g}$. After the adsorption, chitosan/graphene oxide composites could be easily separated and recovered by filtration.

\subsection{Chitosan/Metal Oxides}

There are many types of metal oxide nanoparticles such as zinc oxide $(\mathrm{ZnO})$, magnesium oxide $(\mathrm{MgO})$, magnetite $\left(\mathrm{Fe}_{3} \mathrm{O}_{4}\right)$ and maghemite $\left(\gamma-\mathrm{Fe}_{2} \mathrm{O}_{3}\right)$ that can be used to form chitosan-based composites. Among these metal oxides, $\mathrm{ZnO}$ is cheaper and has higher removal efficiency of organic pollutants than other metal oxides due to its higher semiconducting properties and high surface area [60]. Therefore, $\mathrm{ZnO}$ is commonly used to combine with chitosan to form chitosan/ZnO nanocomposite.

Chitosan/ZnO nanocomposite is a new hybrid material that can more efficiently remove organic pollutants than pure chitosan. Introducing $\mathrm{ZnO}$ nanoparticles into the chitosan matrix can increase the number of active sites on the chitosan surface, resulting in an improvement of the adsorption performance. On the other hand, the modification of chitosan with $\mathrm{ZnO}$ nanoparticles can provide a surface strengthening effect and improve surface corrosion resistance. An experimental study for the removal of organic pollutants was carried out by Arafat et al. [61]. The results showed that chitosan/ $\mathrm{ZnO}$ nanocomposite could remove $95-99 \%$ of organic pollutants by using $2 \mathrm{mg} / \mathrm{L}$ of the composite at the temperature of $50{ }^{\circ} \mathrm{C}$ and contact time of $60 \mathrm{~min}$.

Besides, $\mathrm{MgO}$ nanoparticles can be used for the removal of organic dyes due to their non-toxicity and high chemical stability [62]. However, the biosorption capacity of pure $\mathrm{MgO}$ was reported to be lower, but the contact time required to remove organic dyes was shorter than pure chitosan [63]. Therefore, Nga, Thuy Chau and Viet [64] introduced $\mathrm{MgO}$ nanoparticles in the chitosan matrix in order to remove reactive blue dyes with high biosorption efficiency in a short contact time. The results revealed that chitosan/MgO could remove up to $77.62 \%$ of the reactive blue dyes at the contact time of $120 \mathrm{~min}$, which was shorter than the time required by pure chitosan.

In addition, $\mathrm{Fe}_{3} \mathrm{O}_{4}$ and $\gamma-\mathrm{Fe}_{2} \mathrm{O}_{3}$ are considered iron oxide nanoparticles and they are also known as magnetic materials. They have been widely used to remove organic dyes from wastewater through magnetic separation processes [65]. This might be due to their high thermal stability, chemical stability and biocompatibility, as well as their good magnetic properties [66]. In order to improve the biosorption capacity of chitosan, Zhu et al. [67] and Azari et al. [68] incorporated $\mathrm{Fe}_{3} \mathrm{O}_{4}$ and $\gamma-\mathrm{Fe}_{2} \mathrm{O}_{3}$ in the chitosan matrix to form chitosan $/ \gamma-\mathrm{Fe}_{2} \mathrm{O}_{3}$ and chitosan $/ \mathrm{Fe}_{3} \mathrm{O}_{4} /$ glutaraldehyde composites, respectively. The results indicated that magnetic chitosan composites exhibited higher biosorption capacity and could remove the organic dyes in a shorter contact time ( $<60 \mathrm{~min})$ compared to pure chitosan $(<180 \mathrm{~min})$.

\subsection{Chitosan/Other Biopolymers}

Cellulose is a polysaccharide polymer that can be obtained abundantly from plants, and it is relatively cheap. It can be introduced into a chitosan matrix to form a biopolymer composite. Sun et al. [69] carried out an experimental study to synthesise a chitosan/cellulose composite using ionic liquids to remove organic pollutants from aqueous solution. Based on their results, the adsorption capacity of chitosan/cellulose composite was three times higher than the raw chitosan and cellulose. The chitosan/cellulose composite has a porous structure, larger surface areas, higher stability and higher affinity for organic pollutants [70].

Besides, Li et al. [71] had incorporated polyvinyl alcohol (PVA) in the chitosan matrix to synthesise chitosan/PVA composite as a biosorbent to remove organic dyes. Although PVA has exceptional physicochemical properties, it is not suitable to be utilised as an individual adsorbent because of its low solubility in water and low adsorption capacity for organic dyes [71]. However, chitosan can efficiently adsorb organic dyes due to the presence of a large amount of $-\mathrm{OH}$ and $-\mathrm{NH}_{2}$ groups on its surface. Hence, it is suggested 
to combine the properties of both PVA and chitosan to prepare chitosan/PVA composites. The composites will have high mechanical stability, high performance of adsorption and high chemical resistance in acidic and alkaline solution [41].

\section{Biosorption Parameter Studies}

The biosorption efficiency is affected by many factors, including solution $\mathrm{pH}$, biosorbent dosage, initial pollutant concentration, contact time and solution temperature. However, the effects of these operating parameters are studied individually while maintaining the rest at the constant condition.

\subsection{Effect of Solution PH}

The biosorption capacity of chitosan composite as the biosorbent is highly dependent on the surface charge of chitosan composite and the type of organic dyes in the aqueous solution. The organic dyes can be classified into two types, which are cationic dyes with a positive charge and anionic dyes with a negative charge. It was reported that solution $\mathrm{pH}$ and point zero charge $\left(\mathrm{pH}_{\mathrm{pzc}}\right)$ of chitosan composites were the most critical parameters affecting the biosorption capacity [72]. They have a drastic impact on the surface charge of chitosan composite and ionisation of functional groups present on the chitosan composite surface.

$\mathrm{pH}_{\mathrm{pzc}}$ can be defined as the $\mathrm{pH}$ value at which the net surface charge of chitosan composite is equivalent to zero [73]. Under acidic conditions at low $\mathrm{pH}$, hydrogen ions $\left(\mathrm{H}^{+}\right)$are generated, while hydroxide ions $\left(\mathrm{OH}^{-}\right)$are found under alkaline conditions at high $\mathrm{pH}$. If the solution $\mathrm{pH}$ is more than $\mathrm{pH}_{\mathrm{pzc}}$, the surface of chitosan composite will be negatively charged due to the deprotonation of surface functional groups by $\mathrm{OH}^{-}$at high $\mathrm{pH}$ condition. This will favour the biosorption of cationic dyes through electrostatic attraction. Nevertheless, the positively charged surface of chitosan composite will occur at solution $\mathrm{pH}$ beyond $\mathrm{pH}_{\mathrm{pzc}}$ due to the protonation of surface functional groups. This eventually results in strong electrostatic repulsion between cationic dyes and chitosan composite, thus reducing the biosorption efficiency. Vice versa in the case of anionic dyes, the favourable biosorption condition is attributed to the electrostatic attraction between the negatively charged dyes with the positively charged surface of chitosan composite.

For instance, Kausar et al. [74] reported that the $\mathrm{pH}_{\mathrm{pzc}}$ for chitosan/clay composite was at $\mathrm{pH}$ 7.0. The biosorption capacity of chitosan/clay composite for Rose FRN dyes increased until $\mathrm{pH}$ 10. The results confirmed that the chitosan/clay composite was negatively charged since the optimal solution $\mathrm{pH}$ exceeded $\mathrm{pH}$ 7.0. Equation (1) shows that $\mathrm{OH}^{-}$ deprotonates the $-\mathrm{COOH}$ group on the composite surface and carboxylate ion (-COO-) with negatively charged and water $\left(\mathrm{H}_{2} \mathrm{O}\right)$ are formed under alkaline condition. Moreover, the biosorption mechanism for the removal of cationic dyes at high $\mathrm{pH}$ could be well explained by Equation (2). The negative surface charge of chitosan composites could facilitate electrostatic interaction with the cationic Rose FRN dyes. On the other hand, the $-\mathrm{OH}$ group on the chitosan composite could interact with the cationic dyes through hydrogen bonding. However, the biosorption capacity reduced after $\mathrm{pH} 10$ might be attributed to the excessive $\mathrm{OH}^{-}$reacted with cationic dyes through precipitation.

$$
\begin{gathered}
-\mathrm{COOH}+\mathrm{OH}^{-} \leftrightarrow-\mathrm{COO}^{-}+\mathrm{H}_{2} \mathrm{O} \\
-\mathrm{COO}^{-}+\text {dyes }^{+} \leftrightarrow-\mathrm{COO}-\text { dyes }
\end{gathered}
$$

Besides, there are many types of cationic dyes, including methylene blue, malachite green, methyl violet, crystal violet and so on. A similar finding was reported for the biosorption of methylene blue using chitosan/zeolite, chitosan/bentonite, chitosan/activated carbon, chitosan/silica/ZnO and chitosan/clay composites [54,72-75]. The respective chitosan composite achieved a maximum biosorption capacity at high $\mathrm{pH}$.

In addition, the biosorbents such as chitosan $/ \mathrm{Fe}_{3} \mathrm{O}_{4} /$ graphene oxide, chitosan $/ \mathrm{Fe}_{3} \mathrm{O}_{4} /$ glutaraldehyde and chitosan/ $\mathrm{ZnO}$ composites were employed to remove crystal violet, 
malachite green and methyl violet, respectively $[18,68,76]$. It was observed that their removal efficiencies of cationic dyes also increased at high $\mathrm{pH}$. However, the biosorption efficiency of cationic dyes was reduced at low $\mathrm{pH}$. The low biosorption efficiency might be due to the competition of $\mathrm{H}^{+}$with cationic dyes for the binding sites on the chitosan composite surface under acidic condition.

Next, Travlou et al. [77] studied the effect of $\mathrm{pH}$ for the biosorption of anionic reactive black dyes using chitosan/graphene oxide as the biosorbent. It was reported that the chitosan/graphene oxide exhibited a neutral charge surface when $\mathrm{pH}$ was at 6.8 . The biosorption efficiency of reactive black increased significantly when solution $\mathrm{pH}$ was reduced from 12 to 2 . Hence, chitosan/graphene oxide composite had a positively charged surface as the optimal solution $\mathrm{pH}$ below 6.8. At high $\mathrm{pH}$, the high amount of $\mathrm{OH}^{-}$in the aqueous solution increased the repulsive force between-COO-groups and anionic dyes, resulting in low biosorption efficiency of anionic dyes [78].

The similar findings also reported in the literature for chitosan/MWCNTs, chitosan/PVA, chitosan/cellulose and chitosan/quartzite composites [47,78-80]. The respective chitosan composite was used to remove reactive orange, reactive black, direct blue, eosin yellow and congo red, respectively. These anionic dyes consist of sulphonate $\left(-\mathrm{SO}_{3}{ }^{-}\right)$ groups with negatively charged. When $\mathrm{pH}$ below $\mathrm{pH}_{\mathrm{pzc}},-\mathrm{NH}_{2}$ groups on the chitosan composite surface were protonated to form positively charged amine groups $\left(-\mathrm{NH}_{3}{ }^{+}\right)$ under acidic condition. Consequently, the electrostatic interaction occurred between $-\mathrm{NH}_{3}{ }^{+}$groups of chitosan composite with $-\mathrm{SO}_{3}{ }^{-}$groups of anionic dyes as presented in Equation (3) [77].

$$
-\mathrm{NH}_{3}{ }^{+}+-\mathrm{SO}_{3}{ }^{-} \leftrightarrow-\mathrm{NH}_{3}{ }^{ \pm} \mathrm{O}_{3} \mathrm{~S}
$$

\subsection{Effect of Biosorbent Dosage}

The biosorbent dosage is an important factor in determining the optimum amount or saturation point. At saturation point, any further increment in the amount of biosorbent will not contribute to any significant improvement in the biosorption process. In general, introducing a high amount of biosorbent will increase the availability of vacant biosorption sites and also provide a large surface area for the biosorption of dye molecules [32]. Consequently, a high number of organic dyes can be adsorbed on the biosorbent active site, thereby increasing the removal efficiency of organic dyes.

For instance, the removal efficiency of reactive blue was improved by increasing the chitosan/MgO dosage from 2 to $14 \mathrm{~g} / \mathrm{L}$ [64]. Nevertheless, it was reported that the removal efficiency increased slightly from $58.70 \%$ to $59.82 \%$ when the biosorbent dosage was further increased to $16 \mathrm{~g} / \mathrm{L}$. Hence, it concluded that $14 \mathrm{~g} / \mathrm{L}$ was considered as the optimum biosorbent dosage. The results indicated if the biosorbent dosage exceeded the optimum biosorbent dosage, it would not provide any improvement in the biosorption process due to the unsaturated biosorbent active sites.

Similarly, the biosorption efficiency of methylene blue also increased from $52.52 \%$ to $76.78 \%$ when the chitosan/carbon clay composite was increased from 0.1 to $0.2 \mathrm{~g} / \mathrm{L}$ [81]. However, the biosorption efficiency eventually decreased to $77.24 \%$ when the dosage was $0.3 \mathrm{~g} / \mathrm{L}$. Therefore, the optimal dosage of chitosan/carbon clay composite was determined to be $0.2 \mathrm{~g} / \mathrm{L}$. This might be caused by the overlapping or agglomeration of excessive biosorbent particles that would block the binding sites of another biosorbent. Introducing excessive biosorbent in the biosorption process resulted in an equilibrium imbalance between the vast number of biosorbent binding sites and a constant number of dye molecules [57]. As a result, the biosorption capacity was reduced due to the decrease in the surface area of chitosan composite and the availability of biosorption sites. A similar finding was also reported for chitosan/PVA and chitosan/activated carbon composites [47,82]. The biosorption efficiency of anionic dyes reduced when the biosorbent dosage was added in excess amounts. 


\subsection{Effect of Initial Dye Concentration}

The initial concentration of dyes is also a major influencing factor in the biosorption process which can be studied through biosorption isotherm models. The effect of initial dye concentration on biosorption capacity of chitosan/kaolin clay composite was studied at a constant time of $400 \mathrm{~min}$ with the initial dye concentration studied in the range of $50-400 \mathrm{mg} / \mathrm{L}$ [83]. The results revealed that the biosorption capacity increased with an increase in the initial dye concentration. At the initial biosorption process, more binding sites on the chitosan composite surface were available for the biosorption of dye molecules. Besides, the high initial concentration of dyes provided a greater driving force required to overcome the mass transfer resistance between the liquid phase and solid phase [84]. It could increase the mass transfer of organic dyes to binding sites across the boundary layer of biosorbent particles against the concentration gradient.

However, the biosorption capacity of chitosan composite decreased and remained constant after a period of time. This might be due to the saturation of chitosan composite surface, where dye molecules have occupied most binding sites [71,83]. As a result, excessive dye molecules were not adsorbed on the binding sites due to saturation of binding sites, thus reducing the biosorption capacity. Similar findings also reported in the literature for chitosan/PVA, chitosan/activated carbon and chitosan/MgO composites [64,71,85]. The respective composite also exhibited high biosorption efficiency as increasing the initial dye concentration.

\subsection{Effect of Contact Time}

Contact time is one of the most significant parameters as it can be employed to estimate the biosorption equilibrium and biosorption kinetic models. The contact time can be defined as the time given for the immersion of a given amount of biosorbent at a constant volume and concentration of organic dyes in the solution [86]. According to Muinde et al. [76], the effect of contact time on the biosorption efficiency of cationic dyes was studied at a constant initial dye concentration of $2.3 \mathrm{mg} / \mathrm{L}$ by using chitosan/ZnO composite as the biosorbent. Based on the results, the biosorption rate was significantly accelerated during the first $15 \mathrm{~min}$ with a deeper gradient. This might be due to the abundance of active sites available on the biosorbent surface that could be easily accessed by the organic dyes. Over a period of time, a large number of organic dyes was adsorbed on the active sites of the chitosan composite surface through intermolecular interaction. Muinde et al. [76] also found that the biosorption rate decreased until an equilibrium state was achieved at $180 \mathrm{~min}$ with the maximum biosorption efficiency of $80.10 \%$. The decrease in concentration gradient with contact time could be attributed to a decrease in vacant binding sites for organic dye biosorption. The remaining organic dyes in the solution competed with each other to occupy the remaining active sites on the biosorbent surface. Therefore, sufficient time should be ensured to establish the solid-liquid equilibrium [84]. Besides, Rangabhashiyam, Anu and Selvaraju [85] and Nga, Thuy Chau and Viet [64] also discovered similar findings in which the biosorption rate decreased gradually as contact time increased.

\subsection{Effect of Solution Temperature}

Solution temperature is considered an important parameter that will affect the diffusion rate of sorbates via the external boundary layer surrounding the biosorbent. The information obtained from effect of solution temperature can determine whether the nature of the biosorption process is endothermic or exothermic [87]. In general, the biosorption process at high solution temperatures can increase the collision between the biosorbent and sorbate more frequency, thereby enhancing the biosorption rate. In addition, an increase in solution temperature will decrease the thickness of the boundary layer surrounding the biosorbent. Consequently, the mass transfer resistance of sorbates across the boundary layer is reduced. This will eventually increase the diffusion rate of dye molecules moving from the aqueous phase to the biosorbent surface. 
In the research work conducted by Travlou et al. [77], the chitosan/graphene oxide composite was used as the biosorbent to remove organic dyes. The effect of solution temperature was investigated in the range of 30 to $60{ }^{\circ} \mathrm{C}$. It was reported that the removal efficiency of organic dyes increased when the solution temperature was raised from 30 to $45{ }^{\circ} \mathrm{C}$. The result indicated the dye biosorption was an endothermic process that required a high amount of heat supplied to the process. However, the removal efficiency reduced as the solution temperature was further increased to $60^{\circ} \mathrm{C}$. The excessive heat supplied to the biosorption might lead to the deactivation or the destruction of binding sites on the biosorbent surface [44]. Therefore, the removal efficiency decreased at high solution temperature.

Nevertheless, Kausar et al. [74] discovered a different finding where the biosorption capacity of chitosan/clay decreased with increasing solution temperature from 30 to $60{ }^{\circ} \mathrm{C}$. The result suggested that the biosorption of direct Rose FRN dye was an exothermic process that released heat to the surrounding. Hence, an increase in solution temperature would supply a high amount of heat to the biosorption process, which could deactivate the binding site on the chitosan composite surface. Furthermore, Bahrudin, Nawi and Sabar [88] also observed a similar decreasing trend in the biosorption capacity of chitosan/ montmorillonite when increasing the solution temperature.

\subsection{Comparison Performance for Various Types of Chitosan Composites}

Table 2 compares the performance for various types of chitosan composites used to remove cationic dyes and anionic dyes under different optimum operating conditions. The results revealed that the optimal $\mathrm{pH}$ range for the removal of cationic dyes was between 8 and 11. As for the removal of anionic dyes, the optimal $\mathrm{pH}$ range was found to be between 2 and 6.8 under acidic condition. In addition, all of the biosorption processes were operated in the temperature range of $25-45^{\circ} \mathrm{C}$. It is difficult to compare the performance of chitosan composite accurately due to the differencce in all the operating conditions. However, the biosorption efficiency or organic dyes was mainly affected by solution $\mathrm{pH}$, biosorbent dosage, initial pollutant concentration, contact time and solution temperature as discussed earlier.

Table 2. Removal efficiency of cationic and anionic dyes using various types of chitosan composites under different operating conditions.

\begin{tabular}{|c|c|c|c|c|c|c|c|c|}
\hline $\begin{array}{l}\text { Chitosan } \\
\text { Composites }\end{array}$ & $\begin{array}{l}\text { Cationic/Anionic } \\
\text { Dyes }\end{array}$ & $\mathrm{pH}$ & $\begin{array}{c}\text { Biosorbent } \\
\text { Dosage }(g / L)\end{array}$ & $\begin{array}{c}\text { Initial Dyes } \\
\text { Concentration } \\
(\mathrm{mg} / \mathrm{L})\end{array}$ & $\begin{array}{l}\text { Contact Time } \\
\text { (min) }\end{array}$ & $\begin{array}{c}\text { Temperature } \\
\left({ }^{\circ} \mathrm{C}\right)\end{array}$ & $\begin{array}{l}\text { Dye Removal } \\
\text { Efficiency (\%) }\end{array}$ & References \\
\hline Chitosan/Zeolite & Cationic & 9 & 2.0 & 100 & 138.65 & 30 & 84.85 & $\begin{array}{l}\text { Metin, Çiftçi and } \\
\text { Alver [54] }\end{array}$ \\
\hline \multirow{4}{*}{$\begin{array}{c}\text { Chitosan } / \mathrm{ZnO} \\
\text { Chitosan/Activated } \\
\text { Carbon } \\
\text { Chitosan } / \text { Bentonite } \\
\text { Chitosan } / \mathrm{Fe}_{3} \mathrm{O}_{4} / \\
\text { Graphene Oxide }\end{array}$} & Cationic & 8 & 2.4 & 50 & 180 & 30 & 98.50 & Muinde et al. [76] \\
\hline & Cationic & 11 & 1.0 & 400 & 60 & 30 & 91.02 & Fatombi et al. [82] \\
\hline & Cationic & 10 & 0.2 & 100 & 360 & 25 & 88.00 & Dotto et al. [75] \\
\hline & Cationic & 11 & 1.0 & 100 & 70 & 27 & 87.6 & Tran et al. [18] \\
\hline Chitosan/MgO & Anionic & 6.8 & 9.3 & 100 & 120 & 30 & 79.50 & $\begin{array}{l}\text { Nga, Thuy Chau } \\
\text { and Viet [64] }\end{array}$ \\
\hline Chitosan/PVA & Anionic & 6 & 2.0 & 50 & 40 & 30 & 86.70 & $\begin{array}{c}\text { Anitha, Kumar and } \\
\text { Kumar }\end{array}$ \\
\hline \multirow{3}{*}{$\begin{array}{c}\text { Chitosan/Cellulose } \\
\text { Chitosan/Kaolin } \\
\text { Clay } \\
\text { Chitosan/Graphene } \\
\text { Oxide }\end{array}$} & Anionic & 6.6 & 2.5 & 500 & 625 & 30 & 95.00 & Wang et al. [80] \\
\hline & Anionic & 4 & 0.6 & 140 & 30 & 30 & 99.50 & Xie et al. [53] \\
\hline & Anionic & 2 & 1.0 & 250 & 1440 & 25 & 86.00 & Kamal et al. [89] \\
\hline
\end{tabular}

Among all the parameters studied, solution $\mathrm{pH}$ contributed the significant effects on the dye removal efficiency. This is due to the solution $\mathrm{pH}$ could affect the surface charge of chitosan composite and the type of dyes, eventually affecting dye removal efficiency. The results suggested that the dye removal process was chemisorption $[37,79,90]$, which involved electrostatic interaction and ions exchange between chitosan composite and dye molecules. Besides, the physisorption process depended on the binding sites provided 
by chitosan composite and the amount of dyes adsorbed on the binding sites [89,91]. The physisorption process was mainly affected by biosorbent dosage, initial dye concentration, contact time and solution temperature.

\section{Biosorption Mechanism}

The biosorption process is a mass transfer process that moves substances from the liquid phase (water) to the solid phase (biosorbent). Biosorption can be referred to as the adsorption of sorbates such as atoms, molecules or molecular ions on the surface of solid biological sorbent [92]. Biosorption continues until an equilibrium is reached where the amount of organic dyes adsorbed on the surface of the biosorbent is the same as the amount of organic pollutants left in the solution [51]. In general, it is a physicochemical and metabolism independent process to remove substances from solution by biological materials.

In recent years, the application of biological materials to adsorb and remove organic pollutants from water bodies has attracted a great deal of attention. It has become a hot topic among researchers due to the problems and shortcomings faced by the conventional methods in removing non-biodegradable organic pollutants. Biosorption is characterised by remarkable merits such as ease of modification of biosorbents, high efficiency and low operating and maintenance costs. Another significant benefit of this process is that it does not lead to the generation of intermediate products [93]. The process is reversible, and the adsorbent used can be regenerated by desorption for reuse.

This process can effectively remove organic pollutants even when organic pollutants are in low concentration. This is achieved through the binding of organic pollutants onto the vastly available active binding sites present on the surface of the biosorbent. The detailed biosorption mechanisms were discussed in this section.

The high efficiency of biosorption is a vital aspect that should be characterised to the biosorbent for the effective elimination of various organic dyes. The physicochemical features of the biosorbent vary due to the presence of the different functional groups with varying degrees present on its surface. The most common functional groups present on the biosorbent surface are $-\mathrm{NH}_{2},-\mathrm{COOH},-\mathrm{OH}$ and phosphate group. This respective functional groups can facilitate the sorption of organic dyes on the biosorbent through multiple sorption mechanisms. Figure 4 illustrates the different types of mechanisms involved in the biosorption process. In fact, the interaction between organic dyes and biosorbent surface occurs through electrostatic interaction, ion exchange, complexation, chelation and microprecipitation, physical and chemical adsorption [84].

The biosorption interaction between sorbate and biosorbent mainly occurs in two different conditions: surface sorption and interstitial sorption. Surface sorption involves film diffusion. It occurs when sorbate moves through the bulk solution and diffuse across the liquid film boundary layer surrounding the biosorbent surface. The biosorbent provides numerous active sites for sorbate binding. After that, sorbate is adsorbed on the opposite charged of binding sites on the biosorbent surface [94]. This phenomenon is strongly promoted by Van Der Waals forces, dipole interactions or hydrogen bonding [95]. This process is followed by interstitial sorption. During interstitial sorption, it involves intraparticle diffusion. Sorbate further diffuses into the pores of the biosorbent and eventually attaches to the interior surface of the biosorbent. In this process, film diffusion and intraparticle diffusion are considered as the rate-determining steps whereas the surface bonding takes place in a faster rate [51]. The rate-determining step is defined as the kinetic process occurs at the slowest rate, which eventually affects the overall biosorption rate [79]. As a result, organic dyes require a longer contact time to diffuse from the aqueous phase and internal surface of biosorbents by passing through the biosorbent pores $[27,84]$. Therefore, the rate-determining steps must be determined in order to improve the overall biosorption rate. 


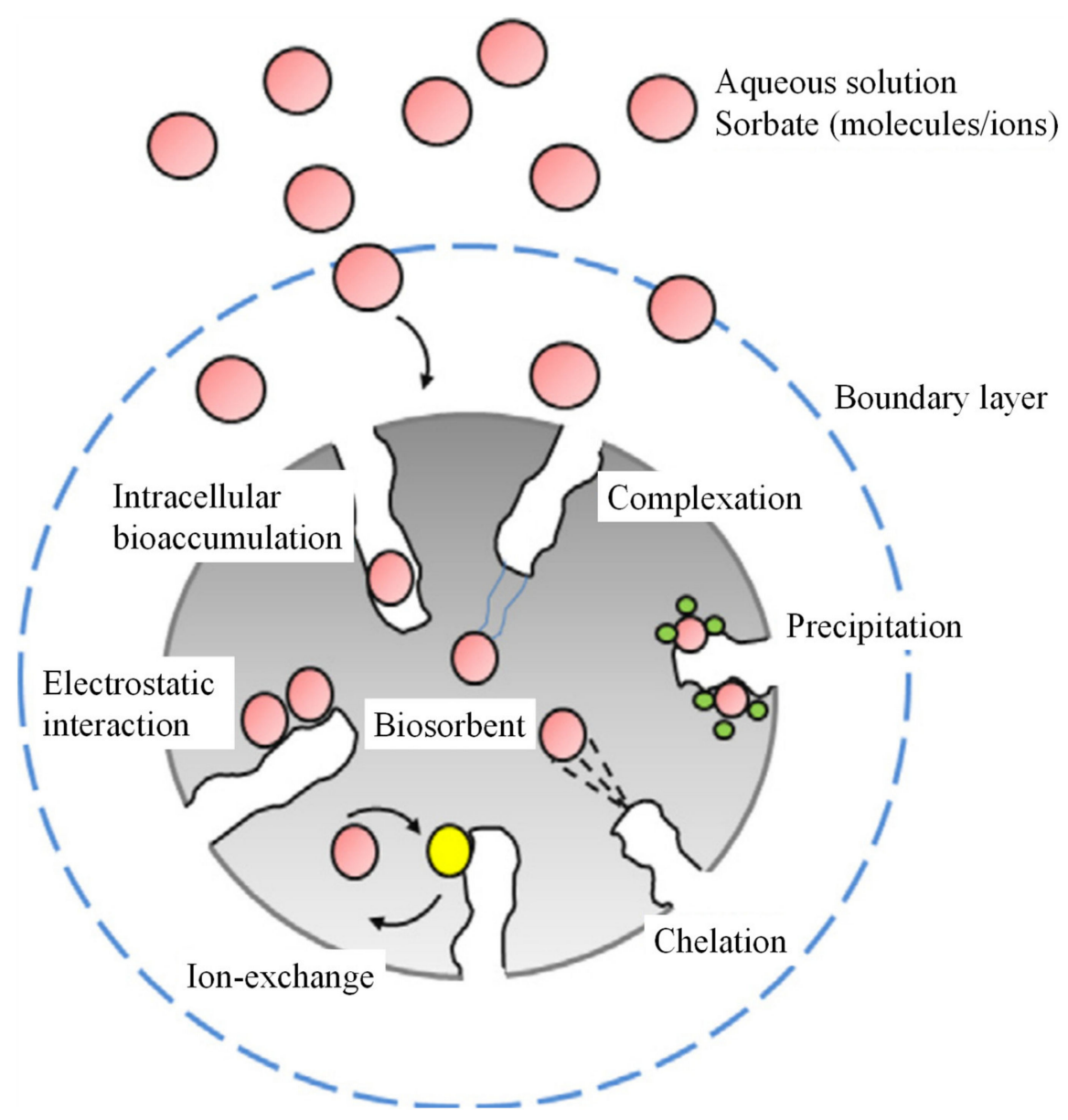

Figure 4. Types of mechanisms in biosorption [84]. Reproduced with permission from Elsevier Science Ltd.

\section{Biosorption Kinetics}

The biosorption kinetic studies are very useful in determining the biosorption rate of dye molecules on the surface of the chitosan composite and the time required to achieve biosorption equilibrium [96]. The kinetic studies are conducted to identify the rate-limiting step and biosorption mechanisms such as mass transfer, diffusion and chemical reaction. Several mathematical models have been employed in the literature to investigate kinetic studies.

In a recent analysis, the fitness of experimental data of dyes removal by chitosan composite was examined using two common kinetic models namely, pseudo-first-order (PFO) and pseudo-second-order (PSO) kinetic models. These kinetic models can evaluate whether the biosorption process involves physisorption or chemisorption as well as investigate the reaction order. The corresponding kinetic models are expressed in Equation (4) and Equation (5) $[8,79]$. The PFO kinetic model reveals that the rate of dye biosorption is proportional to the amount of dye adsorbed on the chitosan composite. The PSO kinetic model shows that the biosorption rate is proportional to the square of the amount of dyes adsorbed on the biosorbent [97].

PFO model linear equation,

$$
\log \left(q_{e}-q_{t}\right)=\log \left(q_{e}\right)-\left(\frac{k_{1}}{2.303}\right) t
$$


PSO model linear equation,

$$
\frac{t}{q_{t}}=\frac{1}{k_{2} q_{e}{ }^{2}}+\left(\frac{1}{q_{e}}\right) t
$$

where

$q_{e}=$ mass of dyes adsorbed per unit mass of chitosan composite at equilibrium condition, $\mathrm{mg} / \mathrm{g}$

$q_{t}=$ mass of dyes adsorbed per unit mass of chitosan composite at any time $t, \mathrm{mg} / \mathrm{g}$

$t=$ contact time, $\mathrm{min}$

$k_{1}=$ rate constant of PFO model, $\mathrm{min}^{-1}$

$k_{2}=$ rate constant of PSO model, $\mathrm{g} /(\mathrm{mg} \cdot \mathrm{min})$

The selection of the kinetic models mainly depends on the fitness of the experimental data based on the coefficient of determination $\left(\mathrm{R}^{2}\right)$ value. Besides, the calculated biosorption at equilibrium value should be close to the experimental biosorption at equilibrium value [98]. If the experiment data is well fitted to the PFO model with a $\mathrm{R}^{2}$ value close to 1 , it suggests that physical sorption will be the rate-limiting step of the biosorption. Vice versa in the case of the PSO model, the rate-limiting step is the chemisorption. In general, the biosorption rate constants and biosorption at equilibrium value of both kinetic models are computed based on the slope and intercept of the graph, respectively. The slope and the intercept of the linear plot of $\log \left(q_{e}-q_{t}\right)$ against $t$ are used to predict the rate constant and biosorption at equilibrium values for the PFO model. As for the PSO model, the rate constant and biosorption at equilibrium values are determined based on the slope and intercept of the linear graph of $t / q_{t}$ against $t[98,99]$.

The kinetic data for the removal of various organic dyes using different types of chitosan composites obtained from the literature are summarised in Table 3. It could be observed that all the biosorption processes studied in the literature were well fitted to the PSO kinetic model with a higher $\mathrm{R}^{2}$ value than the PFO model. Furthermore, the value of biosorption at equilibrium calculated from the PSO model demonstrated a smaller difference with the experimental biosorption at equilibrium value than those calculated from the PFO model. Therefore, these findings suggested that the biosorption of dyes was better defined by the PSO model instead of the PFO model. The findings indicated that the biosorption of dye molecules was dominated by chemical sorption, which involved the sharing of valence forces or electron exchange between the dyes and the active sites on the surface of chitosan composite [79].

Table 3. Kinetic constants of PFO and PSO kinetic models for biosorption of various dyes onto chitosan composites.

\begin{tabular}{|c|c|c|c|c|c|c|c|c|c|}
\hline \multirow{2}{*}{$\begin{array}{l}\text { Chitosan } \\
\text { Composites }\end{array}$} & \multirow[b]{2}{*}{ Type of Dyes } & \multirow{2}{*}{$\begin{array}{c}q_{e, \exp } \\
(\mathrm{mg} / \mathrm{g})\end{array}$} & \multicolumn{3}{|c|}{ PFO Model } & \multicolumn{3}{|c|}{ PSO Model } & \multirow[b]{2}{*}{ References } \\
\hline & & & $\begin{array}{c}q_{e, c a l} \\
(\mathrm{mg} / \mathrm{g})\end{array}$ & $\begin{array}{c}k_{1} \\
\left(\min ^{-1}\right)\end{array}$ & $\mathbf{R}^{2}$ & $q_{e, c a l}(\mathrm{mg} / \mathrm{g})$ & $\begin{array}{c}k_{2} \\
(\mathrm{~g} /(\mathrm{mg} \cdot \min ))\end{array}$ & $\mathbf{R}^{2}$ & \\
\hline \multirow{3}{*}{$\begin{array}{l}\text { Chitosan/Quartzite } \\
\text { Chitosan/Zeolite } \\
\text { Chitosan/Activated } \\
\text { Carbon }\end{array}$} & Reactive Black & 20.15 & 18.91 & 6.100 & 0.9682 & 21.55 & 0.0003 & 0.9918 & \multirow{2}{*}{$\begin{array}{c}\text { Coura, Profeti and Profeti [78] } \\
\text { Dehghani et al. [37] }\end{array}$} \\
\hline & Methylene blue & 23.04 & 7.40 & 0.0820 & 0.8000 & 23.75 & 0.0210 & 0.9970 & \\
\hline & Indigo carmine & 23.98 & 7.80 & 0.7930 & 0.7790 & 2.04 & 0.8650 & 0.9980 & Fatombi et al. [82] \\
\hline $\begin{array}{l}\text { Chitosan/Cellulose } \\
\text { Chitosan/ }\end{array}$ & Congo red & 381.70 & 376.70 & 0.0106 & 0.8552 & 419.20 & $5.04 \times 10^{-6}$ & 0.9529 & Wang et al. [80] \\
\hline $\begin{array}{l}\text { Graphene } \\
\text { Oxide }\end{array}$ & Congo red & 2.53 & 2.53 & 0.2440 & 0.8680 & 2.35 & 0.8650 & 0.9990 & Kamal et al. [91] \\
\hline Chitosan/MgO & Reactive blue & 10.47 & 6.07 & 0.0051 & 0.7287 & 8.55 & 0.0045 & 0.9775 & Nga, Thuy Chau and Viet [64] \\
\hline Chitosan/ZnO & Acid Black 26 & 92.00 & 53.46 & 0.4190 & 0.9360 & 100.00 & 0.0330 & 1.0000 & Salehi et al. [100] \\
\hline Chitosan/Clay & Rose FRN & 12.12 & 12.01 & 0.1770 & 0.9140 & 12.26 & 0.0358 & 0.9560 & Kausar et al. [74] \\
\hline $\begin{array}{l}\text { Chitosan/Kaolin- } \\
\text { Clay }\end{array}$ & Reactive blue & 312.40 & 296.10 & 0.0640 & 0.9200 & 316.60 & 0.0320 & 0.9800 & Jawad et al. [83] \\
\hline Chitosan/MWCNT & Direct blue & 30.12 & 3.90 & 0.0083 & 0.9670 & 30.12 & 0.0007 & 0.9730 & Abbasi and Habibi [79] \\
\hline Chitosan/Alumina & Methyl orange & 41.76 & 10.14 & 0.0490 & 0.8430 & 43.59 & 0.0070 & 0.9990 & Zhang, Zhou and Ou [8] \\
\hline Chitosan/Bentonite & Amido Black 10B & 239.90 & 121.10 & 0.0093 & 0.9840 & 246.90 & 0.0002 & 0.9965 & Liu et al. [101] \\
\hline
\end{tabular}

Among the chitosan composites listed in Table 3, chitosan/cellulose composite demonstrated the highest experimental biosorption at equilibrium value of $381.70 \mathrm{mg} / \mathrm{g}$. This 
might be attributed to the high availability of surface functional groups on chitosan/cellulose such as $-\mathrm{OH}$ and $-\mathrm{COOH}$ groups provided by the cellulose that facilitated the chemical interaction with dye molecules. According to the SEM analysis conducted by Wang et al. [80], the result indicated that chitosan/cellulose composite showed an internal structure with highly porous and multiple membrane layers. Therefore, the high porosity of chitosan/ cellulose composite contributed to a large adsorption site for the biosorption of dyes, resulting in high biosorption capacity.

Since PFO and PSO models could only be employed to evaluate the type of biosorption, therefore the diffusion mechanism of the dye biosorption was studied by applying the intraparticle diffusion model. The respective model was developed by Weber and Morris and expressed in Equation (6) [37,82]. The intraparticle diffusion model can determine the type of biosorption mechanisms that limits the biosorption rate.

Intraparticle diffusion model linear equation,

$$
q_{t}=k_{p} t^{0.5}+C
$$

where

$k_{p}=$ rate constant of intraparticle diffusion, $\mathrm{mg} /\left(\mathrm{g} \cdot \mathrm{min}^{0.5}\right)$

$\mathrm{C}=\mathrm{y}$-intercept of the graph that related to the boundary layer thickness, $\mathrm{mg} / \mathrm{g}$

Generally, the biosorption process was assumed to take place in these three consecutive steps: film diffusion, intraparticle diffusion and biosorption [94]. Firstly, it involved the external mass transfer of dye molecules from the bulk solution across the boundary layer to the external surface of the chitosan composite. Secondly, it involved intraparticle diffusion, where the dye molecules diffused from the external surface to the internal surface of chitosan composite by passing through the pores. Lastly, it was followed by the biosorption of dye molecules on the binding sites of chitosan composite until achieving equilibrium [102].

By plotting the linear graph of $q_{t}$ against $t^{0.5}$, the values of the rate constant of intraparticle diffusion and y-intercept can be obtained from the slope and intercept of the graph. For example, Figure 5 demonstrates the linear plot of $q_{t}$ against $t^{0.5}$ of intraparticle diffusion model for the biosorption of Reactive Blue 5 dyes using chitosan/quartzite composite [80]. Figure 5 shows the biosorption process comprised three sections of the linear line. The first section with a deeper gradient was attributed to the effect of the boundary layer. The organic dye molecules were transported through film diffusion at a high diffusion rate to the external surface of chitosan/cellulose composite. Once the external surface was saturated, the organic dye molecules further diffused through the pore and reached the internal surface of chitosan/cellulose. This phenomenon was resulted from the intraparticle diffusion effect and was represented by the second section with a smaller gradient. Lastly, the equilibrium adsorption of dye molecules on the binding site of chitosan composite occurred in the third section of the linear line.

Similar findings also reported in the literature on the synthesis of chitosan composite with the incorporation of $\mathrm{ZnO}, \gamma-\mathrm{Fe}_{2} \mathrm{O}_{3}$ / silica-oxide, zeolite, PVA and activated carbon $[37,67,82,100,103]$. After conducting the literature studies, the values of the rate constant of intraparticle diffusion and y-intercept for various chitosan composites are tabulated in Table 4. According to the model, if the intraparticle diffusion is the rate-limiting step in the dye biosorption process, the linear line should intercept the origin. However, none of the model lines for the investigated chitosan composites passed through the origin. The greater y-intercept value implied that the biosorption process was influenced not only by the intraparticle diffusion but also by a certain degree of boundary layer [97]. In short, the greater the value of $y$-intercept, the more significant the boundary layer effect. 


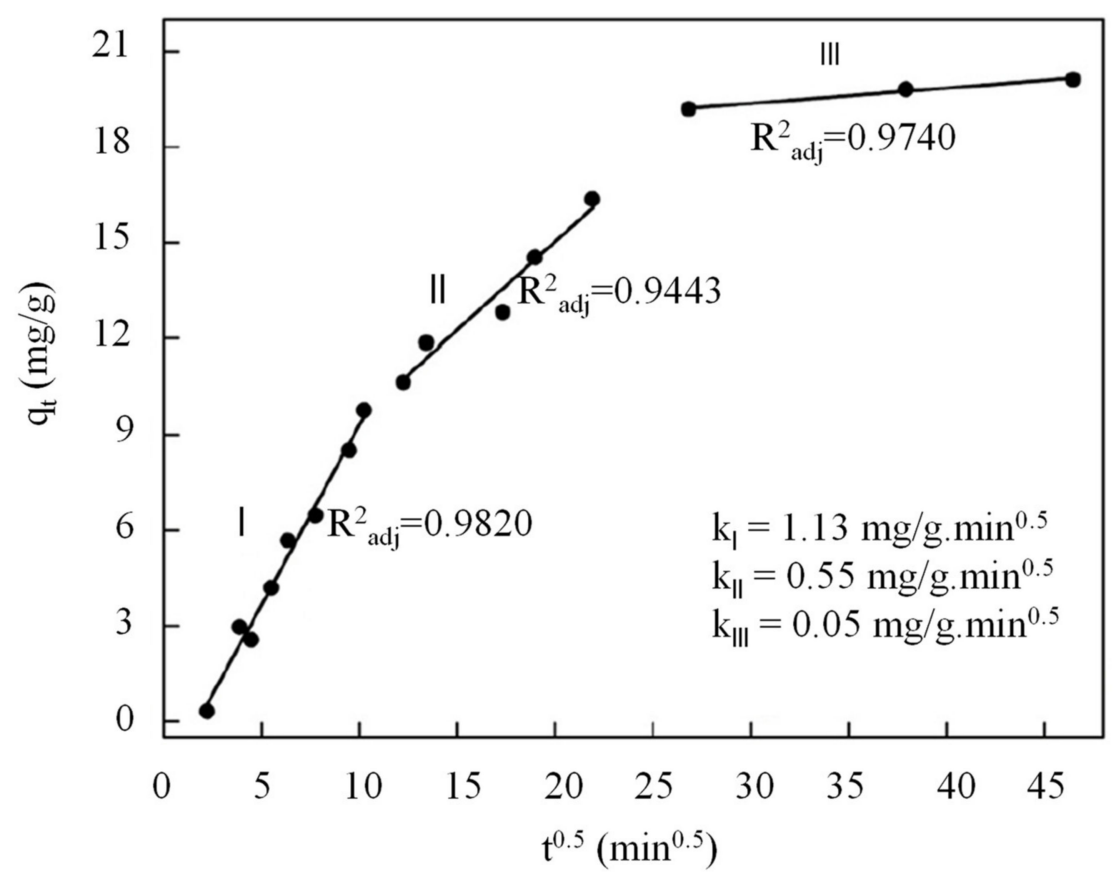

Figure 5. Linear graph of intraparticle diffusion model for biosorption of Reactive Blue 5 by chitosan/quartzite composite [78]. Reproduced with permission from Elsevier Science Ltd.

Table 4. Intraparticle diffusion model parameters for biosorption of dyes by chitosan composites.

\begin{tabular}{|c|c|c|c|c|}
\hline \multirow{2}{*}{ Chitosan Composites } & \multirow{2}{*}{ Types of Dyes } & \multicolumn{2}{|c|}{ Intraparticle Diffusion Model } & \multirow{2}{*}{ References } \\
\hline & & $k_{p}\left(\mathrm{mg} /\left(\mathrm{g} \cdot \mathrm{min}^{0.5}\right)\right)$ & $C(\mathrm{mg} / \mathrm{g})$ & \\
\hline Chitosan/Zeolite & Methylene blue & 0.501 & 19.23 & Dehghani et al. [68] \\
\hline Chitosan/Activated Carbon & Indigo carmine & 1.648 & 20.865 & Fatombi et al. [82] \\
\hline Chitosan/Cellulose & Congo red & 0.1553 & 389.9 & Wang et al. [80] \\
\hline Chitosan/ZnO & Acid black & 12.84 & 38.9 & Salehi et al. [100] \\
\hline Chitosan/PVA & Methyl orange & 1.517 & 9.343 & Habiba et al. [103] \\
\hline Chitosan $/ \gamma-\mathrm{Fe}_{2} \mathrm{O}_{3}$ & Methyl orange & 0.63362 & 14.61 & Zhu et al. [67] \\
\hline
\end{tabular}

\section{Biosorption Isotherms}

The biosorption isotherms are widely used to investigate the interaction type between dye molecules and chitosan composites, as well as to estimate the maximum biosorption capacity. There are two common biosorption isotherm models such as Langmuir and Freundlich isotherm models, which have been employed in the literature to determine the mass of dye molecules adsorbed onto the chitosan composite surface and the equilibrium concentration of dyes [59,94].

The Langmuir isotherm model assumes that the biosorption occurred on the homogenous surface of chitosan composite where the organic dye molecules adsorbed on a constant number of chitosan composite binding sites [91]. Once the binding sites of chitosan composite were saturated, no further biosorption will occur as the maximum biosorption capacity was achieved. A monolayer of molecular thickness was formed on the chitosan composite surface with no interaction between the organic dye molecules. Besides, the adsorption energy and enthalpy were assumed to be distributed equivalent to chitosan composite binding sites [78]. The Langmuir isotherm model can be expressed in non-linear and linear as presented in Equation (7) and Equation (8), respectively [8,79].

Langmuir isotherm model in non-linear form,

$$
q_{e}=\frac{q_{\max } K_{L} C_{e}}{1+K_{L} C_{e}}
$$


Langmuir isotherm model in linear form,

$$
\frac{C_{e}}{q_{e}}=\frac{1}{q_{\max } K_{L}}+\left(\frac{1}{q_{\max }}\right) C_{e}
$$

where

$C_{e}=$ equilibrium concentration of dyes, $\mathrm{mg} / \mathrm{L}$

$q_{\max }=$ maximum biosorption capacity, $\mathrm{mg} / \mathrm{g}$

$K_{L}=$ Langmuir constant, $\mathrm{L} / \mathrm{mg}$

Besides, another important Langmuir constant in the Langmuir isotherm modelnamely, separation factor-can be employed to determine whether the dye biosorption is favourable, non-favourable, linear or irreversible [104]. If the value of separation factor falls within the range between zero and one, it is considered a favourable biosorption process. Otherwise, the biosorption process is considered non-favourable when the separation factor value obtained is more than one. Meanwhile, the biosorption is considered linear when the separation factor value is equal to one and irreversible when the separation factor value is equal to zero. The mathematical representation of separation factor is presented in Equation (9).

Separation factor of Langmuir isotherm model,

$$
R_{L}=\frac{1}{1+K_{L} C_{O}}
$$

$R_{L}=$ separation factor

$C_{o}=$ concentration of dyes at initial process, $\mathrm{mg} / \mathrm{L}$

$K_{L}=$ Langmuir constant, $\mathrm{L} / \mathrm{mg}$

In contrast, the Freundlich isotherm model assumed that the biosorption took place on the heterogeneous surface of chitosan composite with the interaction between multilayer adsorption of dye molecules [90]. It also assumed the adsorption energy was non-uniformly distributed on the chitosan composite surface [78]. The non-linear and linear form of Freundlich isotherm model equations are expressed in Equation (10) and Equation (11), respectively $[8,79]$. The heterogeneity factor is significant in analysing the type of biosorption involved in the biosorption process. The biosorption process is linear when the value of heterogeneity factor is equal to one. Conversely, when heterogeneity factor is less than one or greater than one, the removal of organic dyes involves either chemisorption or physisorption.

Freundlich isotherm model in non-linear form,

$$
q_{e}=K_{F} C_{e}^{\frac{1}{2}}
$$

Freundlich isotherm model in linear form,

$$
\log q_{e}=\log K_{F}+\frac{1}{n} \log C_{e}
$$

where

$n=$ heterogeneity factor

$K_{F}=$ Freundlich constant related to the adsorption capacity, $(\mathrm{mg} / \mathrm{g})(\mathrm{L} / \mathrm{g})^{1 / \mathrm{n}}$

The linear plots for both isotherm models are established using the linear equation instead of the non-linear equation so that the adsorption isotherm parameters can be determined easily from the slope and intercept of the graph. For instance, the isotherm parameter values such as Langmuir constant and maximum biosorption capacity for the Langmuir isotherm model are obtained by plotting $C_{e} / q_{e}$ against $C_{e}$. The slope and intercept of the respective graph represent Langmuir constant and maximum biosorption capacity, respectively. For the Langmuir isotherm model, the heterogeneity factor and Freundlich 
constant values can be computed from the slope and intercept of the linear plot, respectively, by plotting $\log q_{e}$ against $\log C_{e}$.

Table 5 tabulates and summarises the adsorption isotherm parameters of Langmuir and Freundlich isotherm models for the biosorption of dyes using different types of chitosan composites as biosorbents. The results revealed that most of the biosorption process fitted into the Langmuir isotherm model with a higher $\mathrm{R}^{2}$ value than the Freundlich isotherm model. Langmuir isotherm model suggested that a monolayer of dye molecules was formed on the homogeneous surface of chitosan composite and no interaction between the dye molecules. The interaction between dye molecules and chitosan composite was stronger, reflecting that it was chemisorption. Since all of the Langmuir constant values were in the range between zero and one, this indicated that it was a favourable biosorption process.

Table 5. Adsorption isotherm parameters of Langmuir and Freundlich isotherm model for biosorption of various dyes by different types of chitosan composites.

\begin{tabular}{|c|c|c|c|c|c|c|c|c|c|}
\hline \multirow{2}{*}{ Chitosan Composites } & \multirow{2}{*}{ Type of Dyes } & \multirow{2}{*}{$\begin{array}{c}q_{\max } \\
(\mathrm{mg} / \mathrm{g})\end{array}$} & \multicolumn{3}{|c|}{$\begin{array}{c}\text { Langmuir Isotherm } \\
\text { Model }\end{array}$} & \multicolumn{3}{|c|}{ Freundlich Isotherm Model } & \multirow{2}{*}{ References } \\
\hline & & & $\begin{array}{c}K_{L} \\
(\mathrm{~L} / \mathrm{mg})\end{array}$ & $R_{L}$ & $\mathbf{R}^{2}$ & $\begin{array}{c}K_{F} \\
(\mathrm{mg} / \mathrm{g})(\mathrm{L} / \mathrm{g})^{1 / \mathrm{n}}\end{array}$ & $n$ & $\mathbf{R}^{2}$ & \\
\hline Chitosan/Quartzite & Reactive Black & 41.67 & 0.0300 & 0.4762 & 0.9580 & 9.17 & 3.900 & 0.9632 & Dehghani et al. [37] \\
\hline Chitosan/Zeolite & Methylene blue & 24.51 & 0.3030 & 0.1160 & 0.9560 & 8.82 & 3.788 & 0.9990 & Fatombi et al. [82] \\
\hline Chitosan/Activated Carbon & Indigo carmine & 208.33 & 0.0230 & 0.4600 & 0.9954 & 14.18 & 1.190 & 0.9878 & Wang et al. [80] \\
\hline Chitosan/Cellulose & Congo red & 381.70 & 0.2633 & 0.0047 & 0.9729 & 132.90 & 5.488 & 0.8158 & Kamal et al. [91] \\
\hline Chitosan/Graphene Oxide & Congo red & 370.37 & 0.0366 & 0.0546 & 0.9820 & 10.84 & 1.818 & 0.9160 & Coura, Profeti and Profeti [78] \\
\hline Chitosan/ZnO & Acid black & 227.30 & 0.0482 & 0.2075 & 0.9960 & 101.13 & 7.905 & 0.9620 & $\begin{array}{c}\text { Nguyen, Nguyen and } \\
\text { Nguyen [105] }\end{array}$ \\
\hline Chitosan/MgO & Reactive blue & 408.16 & 0.0127 & 0.4400 & 0.9544 & 5.55 & 1.090 & 0.9992 & Nga, Thuy Chau and Viet [64] \\
\hline Chitosan/PVA & Methyl orange & 52.10 & 0.0846 & 0.1912 & 0.9998 & 4.40 & 1.578 & 0.9946 & Habiba et al. [103] \\
\hline Chitosan/Kaolin Clay & Reactive blue & 560.90 & 0.0060 & 0.4167 & 0.9600 & 11.80 & 1.600 & 0.9400 & Jawad et al. [83] \\
\hline Chitosan/MWCNT & Direct blue & 29.33 & 0.3860 & 0.3860 & 0.9980 & 10.42 & 3.650 & 0.9660 & Abbasi and Habibi [79] \\
\hline Chitosan/Alumina & Methyl orange & 32.67 & 0.8210 & 0.8210 & 0.9880 & 11.27 & 2.884 & 0.9720 & Zhang, Zhou and Ou [8] \\
\hline Chitosan/Bentonite & Methylene blue & 496.40 & 0.1660 & 0.0197 & 0.9985 & 170.40 & 5.156 & 0.9251 & Liu et al. [101] \\
\hline
\end{tabular}

However, some researchers found that the biosorption processes using chitosan/ quartzite [78], chitosan/zeolite [37] and chitosan/MgO [64] as biosorbents followed the Freundlich isotherm model with a higher $\mathrm{R}^{2}$ value than the Langmuir isotherm model. The findings implied that the biosorption of dyes occurred on the heterogeneous surface. The interaction occurred between the dye molecules with chitosan composite and between the adsorbed dye molecules, resulting in the formation of multilayer molecular thickness. This was due to the presence of impurities adsorbed on the chitosan composites during the modification of pure chitosan [59]. The impurities on the chitosan composite surface would cause different level of binding energy for the biosorption of organic dyes. The calculated heterogeneity factor values were more than one which indicated the removal of dyes involved physisorption.

For the comparison of maximum biosorption capacity values, chitosan/kaolin clay composite possessed the highest maximum biosorption capacity value of $560.90 \mathrm{mg} / \mathrm{g}$ among the chitosan composites listed in Table 5 . This might be due to the availability of $-\mathrm{OH}$, silanol, and aluminol function groups on the surface chitosan/kaolin clay composite, which was attributed by kaolin clay [106]. These additional surface functional groups corresponded to cellulose served as adsorption sites to interact electrostatically with the organic dye molecules and maximise the biosorption capacity. The rough and irregular surface of chitosan/kaolin clay composite also helped to promote the biosorption of dyes.

In contrast, chitosan/zeolite composite exhibited the lowest maximum biosorption capacity value of $24.51 \mathrm{mg} / \mathrm{g}$ for the removal of methylene blue dyes as compared to the other chitosan composites. As suggested by the Freundlich isotherm model, the biosorption of methylene blue occurred on the heterogeneous surface of chitosan/zeolite composite. The removal of methylene blue was dominated by the physisorption process rather than the chemisorption process. Hence, the weak intermolecular interaction between the biosorbent 
and organic dye molecules, as well as between the dye molecules, might be broken easily. This might be attributed to the collision between dye molecules as the dye concentration and solution temperature increased [53]. Consequently, the dye molecules were desorbed from the chitosan/zeolite surface and remained in the aqueous solution, resulting in lower adsorption capacity.

\section{Biosorption Thermodynamics}

Thermodynamic studies are usually carried out to investigate the effect of temperature on the dye biosorption process. Besides, the studies also provide detailed insight information on the feasibility, spontaneity and nature of the biosorption process as well as the orderliness of organic dyes molecules at the solid-liquid interface [107]. This information can be obtained by determining the thermodynamic parameters such as Gibb's free energy change $\left(\Delta G^{\circ}\right.$ in $\left.\mathrm{kJ} / \mathrm{mol}\right)$, enthalpy change $\left(\Delta H^{\circ}\right.$ in $\left.\mathrm{kJ} / \mathrm{mol}\right)$ and entropy change $\left(\Delta S^{\circ}\right.$ in $\mathrm{J} /(\mathrm{mol} \cdot \mathrm{K}))$. The corresponding thermodynamic parameters can be computed by using the mathematical formulas from Equation (12) to Equation (14) [103,108,109].

$$
\begin{gathered}
K_{C}=\frac{C_{s}}{C_{e, m}} \\
\Delta G^{\circ}=-R T \ln K_{c} \\
\ln K_{F}=\frac{\Delta S^{\circ}}{R}-\frac{\Delta H^{\circ}}{R T}
\end{gathered}
$$

here

$C_{S}=$ equilibrium concentration of dyes remaining in aqueous solution, $\mathrm{mg} / \mathrm{L}$

$C_{e, m}=$ mass of dyes molecules adsorbed per unit mass of chitosan composite at equilibrium, $\mathrm{mg} / \mathrm{g}$

$R=$ gas constant $(8.314 \mathrm{~J} /(\mathrm{mol} \cdot \mathrm{K}))$

$T=$ absolute temperature, $\mathrm{K}$

For instance, Gibb's free energy change value is calculated by substituting Equation (12) into Equation (13) once the equilibrium constant $\left(K_{c}\right)$ has been determined. Next, Equation (14) shows the van't Hott equation that can be used to calculate the energy change of the biosorption process. The value of enthalpy change and entropy change can be obtained from the slope and intercept of the graph by plotting $\ln K_{c}$ against $1 / T$.

The thermodynamic parameters for the biosorption of dyes using various chitosan composite were collected from different literature and summarised in Table 6. The enthalpy change is generally utilised to evaluate whether the nature of biosorption is an exothermic or endothermic process. The biosorption of dyes is an exothermic process if the measured enthalpy change is negative value; otherwise, it is an endothermic process [110]. 
Table 6. Thermodynamic parameters for biosorption of dyes using various type of chitosan composites.

\begin{tabular}{|c|c|c|c|c|c|c|c|}
\hline $\begin{array}{l}\text { Chitosan } \\
\text { Composites }\end{array}$ & Type of Dyes & $\begin{array}{l}\text { Equilibrium } \\
\text { Constant, } K_{c}\end{array}$ & $\begin{array}{c}\text { Gibbs' Free } \\
\text { Energy } \\
\text { Change } \Delta G^{\circ} \\
(\mathbf{k J} / \mathbf{m o l})\end{array}$ & $\begin{array}{c}\text { Enthalpy } \\
\text { Change } \Delta H^{\circ} \\
\text { (kJ/mol) }\end{array}$ & $\begin{array}{l}\text { Entropy } \\
\text { Change } \Delta S^{\circ} \\
\text { (J/K/mol) }\end{array}$ & $\begin{array}{c}\text { Temperature, } \\
T(K)\end{array}$ & References \\
\hline Chitosan/Quartzite & Reactive black & $4.943 \times 10^{4}$ & -25.88 & 21.76 & 166.50 & 288 & Dehghani et al. [37] \\
\hline $\begin{array}{c}\text { Chitosan/Activated } \\
\text { Carbon }\end{array}$ & Indigo carmine & $1.090 \times 10^{4}$ & -23.42 & 10.66 & 112.40 & 303 & Wang et al. [80] \\
\hline Chitosan/Cellulose & Congo red & 7.899 & -5.209 & 86.25 & 300.90 & 303 & Kamal et al. [91] \\
\hline Chitosan/MgO & Reactive blue & $7.956 \times 10^{3}$ & -21.73 & 14.56 & 0.1250 & 291 & $\begin{array}{l}\text { Nga, Thuy Chau } \\
\text { and Viet [64] }\end{array}$ \\
\hline Chitosan/PVA & Eosin yellow & 7.743 & -5.156 & -7.486 & -7.716 & 303 & Habiba et al. [103] \\
\hline $\begin{array}{l}\text { Chitosan/Zeolite } \\
\text { Crosslinked }\end{array}$ & Methyl orange & 2.730 & -2.530 & 7.179 & 34.3048 & 283 & Hussain et al. [109] \\
\hline $\begin{array}{l}\text { Chitosan } \\
\text { Epichlorohydrin }\end{array}$ & Reactive red & 2.593 & -2.400 & 27.7 & 0.0990 & 303 & Jawad et al. [108] \\
\hline $\begin{array}{c}\text { Chitosan/Kaolin } \\
\text { Clay }\end{array}$ & Reactive blue & 6.063 & -4.540 & 4.810 & 0.4300 & 303 & Jawad et al. [83] \\
\hline Chitosan/Alumina & Methyl orange & 5.335 & -4.148 & -10.54 & -21.59 & 298 & $\begin{array}{c}\text { Zhang, Zhou and } \\
\text { Ou [8] }\end{array}$ \\
\hline Chitosan/Bentonite & Amido black & 1.116 & -0.2670 & 15.78 & 0.0547 & 293 & Liu et al. [101] \\
\hline Chitosan $/ \gamma-\mathrm{Fe}_{2} \mathrm{O}_{3}$ & Methyl orange & 1.939 & -1.762 & -17.41 & -48.89 & 320 & Zhu et al. [67] \\
\hline
\end{tabular}

Next, the biosorption process is considered favourable and spontaneous when the obtained Gibb's free energy change is in negative magnitude. Besides, Gibb's free energy change is also helpful in determining whether the biosorption is occurred either physically or chemically. If the value of Gibb's free energy change lies between $-20 \mathrm{~kJ} / \mathrm{mol}$ and $0 \mathrm{~kJ} / \mathrm{mol}$, this indicates the type of biosorption is physisorption. However, if the Gibb's free energy change value is within the range of $-80 \mathrm{~kJ} / \mathrm{mol}$ to $-400 \mathrm{~kJ} / \mathrm{mol}$, the biosorption of dyes involves chemisorption [74]. Lastly, the orderliness at the solid-liquid interface increases with the increasing entropy change value.

Based on the results as shown in Table 6, it was observed that all the biosorption processes using various chitosan composites had the negative value of Gibb's free energy change, reflecting that the biosorption processes were feasible and spontaneous at the low temperature range between 288 and $320 \mathrm{~K}$. In addition, most of the organic dye biosorption processes was physisorption type since their Gibb's free energy change values were within the range of -20 to $0 \mathrm{~kJ} / \mathrm{mol}$. The Gibb's free energy change values of chitosan/quartzite, chitosan/activated carbon and chitosan/ $\mathrm{MgO}$ composites were -25.88 , -23.42 and $-21.73 \mathrm{~kJ} / \mathrm{mol}$, respectively, which were in the range of -20 and $-80 \mathrm{~kJ} / \mathrm{mol}$. These values indicated that the physical adsorption was influenced by certain chemical effects and implied that ion exchange might occur during the biosorption process [111,112].

Moreover, most of the biosorption processes with a positive value of enthalpy change revealed that it was an endothermic process that required input energy supplied to the process. The endothermic nature of organic dye biosorption might be attributed to the dehydration process, where additional energy was required to remove the water molecules adsorbed on the surface of chitosan composite. Meanwhile, the desorption of water molecules could provide a larger surface area for the biosorption of organic dyes on the chitosan composite surface [37]. Among the chitosan composite, chitosan/cellulose had the highest positive enthalpy change value due to the membrane layer of cellulose entrapped with a high amount of water molecules, thereby increasing the energy for the removal of water molecules.

However, chitosan/PVA, chitosan/alumina and chitosan $/ \gamma-\mathrm{Fe}_{2} \mathrm{O}_{3} /$ silica oxide composites as the biosorbents for the organic dye removal demonstrated a different finding with a negative enthalpy change value. The finding suggested that the biosorption process was exothermic, where the organic dye molecules interacted with the surface functional groups of chitosan composites through electrostatic attraction, hydrogen bonding and weak intermolecular interaction. Consequently, the surface energy of chitosan composite was reduced and the output energy was released to the surrounding [8]. 
Furthermore, the biosorption process with a positive magnitude of entropy change reflected that the dye molecules had a good interaction with the chitosan composite. Consequently, this resulted in an increase in the irregularity of dye molecules at the solidliquid interface. Conversely, the irregularity of dye molecules decreased when a negative entropy change was obtained $[67,101]$.

\section{Future Prospects and Conclusions}

This work reviewed the results achieved by numerous researchers on the removal of organic dyes through biosorption process. The aim of this review is to present the potential of utilisation chitosan composites as low-cost adsorbent for textile wastewater treatment and to attract more research on large scale applicability. Biosorption using chitosan-based adsorbent stands out as one of the most attractive organic dyes removal methods in terms of cost-benefit and efficient performance. The utilisation concept of converting waste to wealth can promote sustainability in the wastewater treatment research field.

Chitosan-based adsorbent with higher specific surface area, appropriate pore size and pore volume and multiple functional groups such as hydroxyl, carboxyl and amine groups are beneficial for the effective and efficient removal of organic dyes. This article presented the biosorption parameter study, mechanisms involved in the processes, addressing kinetics, isotherms and thermodynamics. Factors such as solution $\mathrm{pH}$, biosorbent dosage, initial dye concentration, contact time and solution temperature are those significant parameters that affect the biosorption efficiency. Modelling revealed that most of biosorption studies described by the PSO model, while the Langmuir and Freundlich isotherm equations have been successfully applied to many adsorption processes. Thermodynamics data demonstrated that biosorption of organic dyes using various types of chitosan composites are spontaneous and endothermic processes. The high molecular weight chitosan with thermally and chemically stable properties often encountered aggregation and polymeric chain entanglements during adsorption. Hence, recent research also focusses on the preparation of low molecular weight of chitosan, to improve the solubility of chitosan and to expand its potential applications in more extensive fields.

Even though the biosorption process is an efficient and cost-effective technique for the removal of organic dyes, it experiences a little more challenging to demonstrate it at large-scale commercial applications which would involve a significant financial and technological effort. Most of the chitosan biosorbents are in used the suspended form and the post-separation of suspended biosorbent from the treated effluent was extremely difficult, which are not effective and durable for a long-term environmental application. This would cause problems related to the recyclability, regeneration and maintenance of the used biosorbent stability, which restrict its application in the suspended form for the removal of organic dyes from wastewater. Limited number of investigations had been conducted in the large-scale application for biosorption of organic dyes in wastewater. Almost all the research works were performed in a laboratory batch scale, indicating a long journey ahead before implementation of the biosorption technology in real industry wastewater.

In order to overcome the drawbacks associated with the suspended form of the biosorbents, a greater number of studies need to be focused on the developing of immobilised, magnetic chitosan biosorbents or fixed-bed dynamic tests. These types of biosorbents can be separated out easily and/or recovered from treated medium after the biosorption process within a short time. The recovery and regeneration through desorption is a critical to evaluate the biosorbent recyclability together with the adsorption-desorption cycles, which aimed to be used in commercial/industrial scale later. A well-planned regeneration and management of biosorbent can reduce environmental impact and clogging issue, as well as enhance/maintain its stability, mechanical strength and bioremediation capacity.

Biosorption of real textile wastewater in fixed-bed column or continuous systems need to be conducted to evaluate the actual removal efficiency of a biosorbent and account for the multi-solute scenarios present in the real industry wastewater. The main criteria such 
as high adsorption rate and capacity, effectiveness separation, robustness and stability also need to be considered when designing the biosorbent, so that the biosorbent can be applied in a hash condition with minimal/ no leaching of harmful materials to the environment. Biosorbent surface need to be modified properly to strengthen the surface functional groups and improve the process efficiency of organic dyes. The supply chain for the raw materials of biomass-based chitosan biosorbent needs to be increased and explored, while nurturing the local expertise for effective chitosan production. It is also important to study the life cycle assessment on biosorption process and adsorbent in order to evaluate the impacts towards environment and human beings. An economic assessment of the chitosan-based in a large-scale biosorption system that aims at industrial application is an essential activity to ascertain and assess the feasibility of its future in wastewater treatment.

Author Contributions: Conceptualization, writing-review and editing, Y.L.P.; data curation, writing-original draft preparation, J.H.T.; methodology, resources, S.L.; visualization, W.C.C. All authors have read and agreed to the submitted version of the manuscript.

Funding: This research was funded by Ministry of Education (MOE) Malaysia that provided the Fundamental Research Grant Scheme (FRGS/1/2018/TK10/UTAR/02/2) and Universiti Tunku Abdul Rahman (UTAR) Research Fund (IPSR/RMC/UTARRF/2020-C2/P01).

Acknowledgments: The authors would like to thank the Ministry of Education (MOE) Malaysia that provided the Fundamental Research Grant Scheme (FRGS/1/2018/TK10/UTAR/02/2) and the Universiti Tunku Abdul Rahman (UTAR) Research Fund (IPSR/RMC/UTARRF/2020-C2/P01) for the financial support.

Conflicts of Interest: The authors declare no conflict of interest.

\section{References}

1. Bidaisee, S. The Importance of Clean Water. Biomed. J. Sci. Tech. Res. 2018, 8, 6780-6783. [CrossRef]

2. Department of Environment (DOE). River Water Quality. Available online: https://www.doe.gov.my/portalv1/en/frm-kualitiair-sungai-2 (accessed on 10 August 2021).

3. Marotta, A.; Luzzi, E.; de Luna, M.S.; Aprea, P.; Ambrogi, V.; Filippone, G. Chitosan/Zeolite Composite Aerogels for a Fast and Effective Removal of Both Anionic and Cationic Dyes from Water. Polymers 2021, 13, 1691. [CrossRef] [PubMed]

4. Berradi, M.; Hsissou, R.; Khudhair, M.; Assouag, M.; Cherkaoui, O.; El Bachiri, A.; El Harfi, A. Textile Finishing Dyes and Their Impact on Aquatic Environs. Heliyon 2019, 5, e02711. [CrossRef] [PubMed]

5. Tovey, C.; Meijer, S. The Bangladesh Responsible Sourcing Initiative: A New Model for Green Growth; The World Bank: Washington, DC, USA, 2014; pp. 1-100.

6. Kausar, A.; Iqbal, M.; Javed, A.; Aftab, K.; Nazli, Z.-H.; Bhatti, H.N.; Nouren, S. Dyes adsorption using clay and modified clay: A review. J. Mol. Liq. 2018, 256, 395-407. [CrossRef]

7. Lellis, B.; Fávaro-Polonio, C.Z.; Pamphile, J.A.; Polonia, J.C. Effects of Textile Dyes on Health and the Environment and Bioremediation Potential of Living Organisms. Biotechnol. Res. Innov. 2019, 3, 275-290. [CrossRef]

8. Zhang, J.; Zhou, Q.; Ou, L. Kinetic, Isotherm, and Thermodynamic Studies of the Adsorption of Methyl Orange from Aqueous Solution by Chitosan/Alumina Composite. J. Chem. Eng. Data 2012, 57, 412-419. [CrossRef]

9. Gautam, R.K.; Mudhoo, A.; Lofrano, G.; Chattopadhyaya, M.C. Biomass-derived Biosorbents for Metal Ions Sequestration: Adsorbent Modification and Activation Methods and Adsorbent Regeneration. J. Environ. Chem. Eng. 2014, 2, 239-259. [CrossRef]

10. Tsang, Y.F.; Kumar, V.; Samadar, P.; Yang, Y.; Lee, J.; Ok, Y.S.; Song, H.; Kim, K.H.; Kwon, E.E.; Jeon, Y.J. Production of Bioplastic through Food Waste Valorization. Environ. Int. 2019, 127, 625-644. [CrossRef]

11. Knidri, H.E.; Belaabed, R.; Addaou, A.; Laajeb, A.; Lahsini, A. Extraction, Chemical Modification and Characterization of Chitin and Chitosan. Int. J. Biol. Macromol. 2018, 120, 1181-1189. [CrossRef]

12. Sivanesan, I.; Gopal, J.; Muthu, M.; Shin, J.; Mari, S.; Oh, J. Green Synthesized Chitosan/Chitosan Nanoforms/Nanocomposites for Drug Delivery Applications. Polymers 2021, 13, 2256. [CrossRef]

13. El-Ghoul, Y.; Ammar, C.; Alminderej, F.M.; Shafiquzzaman, M. Design and Evaluation of a New Natural Multi-Layered Biopolymeric Adsorbent System-Based Chitosan/Cellulosic Nonwoven Material for the Biosorption of Industrial Textile Effluents. Polymers 2021, 13, 322. [CrossRef]

14. Thamer, B.M.; Aldalbahi, A.; Moydeen, M.A.; El-Newehy, M.H. In Situ Preparation of Novel Porous Nanocomposite Hydrogel as Effective Adsorbent for the Removal of Cationic Dyes from Polluted Water. Polymers 2020, 12, 3002. [CrossRef] [PubMed]

15. Sanchez-Vazquez, S.A.; Hailes, H.C.; Evans, J.R.G. Hydrophobic Polymers from Food Waste: Resources and Synthesis. Polym. Rev. 2013, 53, 627-694. [CrossRef] 
16. Hernández, N.; Williams, R.C.; Cochran, E.W. The Battle for the "Green" Polymer. Different Approaches for Biopolymer Synthesis: Bioadvantaged vs. Bioreplacement. Org. Biomol. Chem. 2014, 12, 2834-2849. [CrossRef]

17. Ventorino, V.; Robertiello, A.; Cimini, D.; Argenzio, O.; Schiraldi, C.; Montella, S.; Faraco, V.; Ambrosanio, A.; Viscardi, S.; Pepe, O. Bio-based Succinate Production from Arundo Donax Hydrolysate with the New Natural Succinic Acid-producing Strain Basfia Succiniciproducens BPP7. Bioenergy Res. 2017, 10, 488-498. [CrossRef]

18. Tran, H.V.; Bui, L.T.; Dinh, T.T.; Le, D.H.; Huynh, C.D.; Trinh, A.X. Graphene Oxide $/ \mathrm{Fe}_{3} \mathrm{O}_{4} /$ Chitosan Nanocomposite: A Recoverable and Recyclable Adsorbent for Organic Dyes Removal. Application to Methylene Blue. Mater. Res. Express 2017, 4, 401-411. [CrossRef]

19. Criado-Gonzalez, M.; Mijangos, C.; Hernández, R. Polyelectrolyte Multilayer Films Based on Natural Polymers: From Fundamentals to Bio-Applications. Polymers 2021, 13, 2254. [CrossRef] [PubMed]

20. Poli, A.; Anzelmo, G.; Fiorentino, G.; Nicolaus, B.; Tommonaro, G.; Di, P. Polysaccharides from Wastes of Vegetable Industrial Processing: New Opportunities for their Eco-friendly Re-use. Biotechnol. Biopolym. 2011, 365, 33-56.

21. Crini, G.; Lichtfouse, E. Advantages and Disadvantages of Techniques Used for Wastewater Treatment. Environ. Chem. Lett. 2019, 17, 145-155. [CrossRef]

22. Saratale, G.D.; Jung, M.Y.; Oh, M.K. Reutilization of Green Liquor Chemicals for Pretreatment of Whole Rice Waste Biomass and its Application to 2, 3-butanediol Production. Bioresour. Technol. 2016, 205, 90-96. [CrossRef]

23. Kanmani, P.; Aravind, J.; Kamaraj, M.; Sureshbabu, P.; Karthikeyan, S. Environmental Applications of Chitosan and Cellulosic Biopolymers: A Comprehensive Outlook. Bioresour. Technol. 2017, 242, 295-303. [CrossRef]

24. Niaounakis, M. Biopolymers: Reuse, Recycling and Disposal, 1st ed.; William Andrew: Waltham, MA, USA, 2013.

25. Wang, X.; Zhu, C.S.; Chen, C.Z.; Zhang, H.; Wang, D.; Ma, Y.Y. Recent Developments in Treatment of Chromium-contaminated Wastewater by Starch-based Adsorbents. Adv. Mater. Res. 2013, 781, 2120-2123. [CrossRef]

26. Ibrahim, S.; Riahi, O.; Said, S.M.; Sabri, M.F.M.; Rozali, S. Biopolymers From Crop Plants. In Reference Module in Materials Science and Materials Engineering; Elsevier: Hoboken, NJ, USA, 2019; pp. 1-10.

27. Shukla, S.K.; Mishra, A.K.; Arotiba, O.A.; Mamba, B.B. Chitosan-based Nanomaterials: A State-of-the-art Review. Int. J. Biol. Macromol. 2013, 59, 46-58. [CrossRef] [PubMed]

28. Perez-Madrigal, M.M.; Edo, M.G.; Aleman, C. Powering the Future: Application of Cellulose-based Materials for Supercapacitors. Green Chem. 2016, 18, 5930-5956. [CrossRef]

29. Sarode, S.; Upadhyay, P.; Khosa, M.A.; Mak, T.; Shakir, A.; Song, S.; Ullah, A. Overview of Wastewater Treatment Methods with Special Focus on Biopolymer Chitin-chitosan. Int. J. Biol. Macromol. 2019, 121, 1086-1100. [CrossRef] [PubMed]

30. Ghormade, V.; Pathan, E.K.; Deshpande, M.V. Can Fungi Compete with Marine Sources for Chitosan Production? Int. J. Biol. Macromol. 2017, 104, 1415-1421. [CrossRef] [PubMed]

31. Rafique, A.; Mahmood Zia, K.; Zuber, M.; Tabasum, S.; Rehman, S. Chitosan Functionalized Poly(vinyl alcohol) for Prospects Biomedical and Industrial Applications: A Review. Int. J. Biol. Macromol. 2016, 87, 141-154. [CrossRef]

32. Al-Manhel, A.J.; Al-Hilphy, A.R.S.; Niamah, A.K. Extraction of Chitosan, Characterisation and its use for Water Purification. J. Saudi Soc. Agric. Sci. 2018, 17, 186-190. [CrossRef]

33. Obiora-Okafo, I.A.; Onukwuli, O.D. Optimization of Coagulation-flocculation for Colour Removal from Azo Dye using Natural Polymers: Response Surface Methodological Approach. Niger. J. Technol. 2017, 36, 482-495. [CrossRef]

34. Cao, Y.L.; Pan, Z.H.; Shi, Q.X.; Yu, J.Y. Modification of Chitin with High Adsorption Capacity for Methylene Blue removal. Int. J. Biol. Macromol. 2018, 114, 392-399. [CrossRef]

35. Farias, P.V.S.; Aragão, D.C.; Farias, M.V.; Correia, L.M.; Carvalho, T.V.; Aguiar, J.E.; Vieira, R.S. Natural and Cross-linked Chitosan Spheres as Adsorbents for Diesel Oil Removal. Adsorpt. Sci. Technol. 2015, 33, 783-792. [CrossRef]

36. Elanchezhiyan, S.S.D.; Muthu Prabhu, S.; Meenakshi, S. Treatment of Emulsified Oil using Biopolymer Assisted Materials. Polym. Compos. 2018, 39, 261-270. [CrossRef]

37. Dehghani, M.H.; Dehghan, A.; Alidadi, H.; Dolatabadi, M.; Mehrabpour, M.; Converti, A. Removal of Methylene Blue Dye from Aqueous Solutions by a New Chitosan/zeolite Composite from Shrimp Waste: Kinetic and Equilibrium Study. Korean J. Chem. Eng. 2017, 34, 1699-1707. [CrossRef]

38. Thakur, M.K.; Rana, A.K.; Liping, Y.; Singha, A.S.; Thakur, V.K. Surface Modification of Biopolymers: An Overview. In Surface Modification of Biopolymers; John Wiley and Sons: Hoboken, NJ, USA, 2015; Volume 52, pp. 1-19.

39. Younes, I.; Rinaudo, M. Chitin and Chitosan Preparation from Marine Sources. Structure, Properties and Applications. Mar. Drugs 2015, 13, 1133-1174. [CrossRef] [PubMed]

40. Thakur, V.K.; Thakur, M.K.; Gupta, R.K. Development of Functionalized Cellulosic Biopolymers by Graft Copolymerization. Int. J. Biol. Macromol. 2013, 62, 44-51. [CrossRef]

41. Khademian, E.; Salehi, E.; Sanaeepur, H.; Galiano, F.; Figoli, A. A Systematic Review on Carbohydrate Biopolymers for Adsorptive Remediation of Copper Ions from Aqueous Environments-Part A: Classification and Modification Strategies. Sci. Total Environ. 2020, 738, 139829. [CrossRef] [PubMed]

42. Kyzas, G.Z.; Kostoglou, M.; Lazaridis, N.K.; Bikiaris, D.N. N-(2-Carboxybenzyl) Grafted Chitosan as Adsorptive Agent for Simultaneous Removal of Positively and Negatively Charged Toxic Metal Ions. J. Hazard. Mater. 2013, 244, 29-38. [CrossRef] 
43. Rezakazemi, M.; Ebadi Amooghin, A.; Montazer-Rahmati, M.M.; Ismail, A.F.; Matsuura, T. State-of-the-art Membrane based CO 2 Separation using Mixed Matrix Membranes (MMMs): An Overview on Current Status and Future Directions. Prog. Polym. Sci. 2014, 39, 817-861. [CrossRef]

44. Wang, J.; Chen, C. Chitosan-based Biosorbents: Modification and Application for Biosorption of Heavy Metals and Radionuclides. Bioresour. Technol. 2014, 160, 129-141. [CrossRef] [PubMed]

45. Nagireddi, S.; Katiyar, V.; Uppaluri, R. Pd(II) Adsorption Characteristics of Glutaraldehyde Cross-linked Chitosan Copolymer Resin. Int. J. Biol. Macromol. 2017, 94, 72-84. [CrossRef]

46. Kim, M.H.; An, S.; Won, K.; Kim, H.J.; Lee, S.H. Entrapment of Enzymes into Cellulose-Biopolymer Composite Hydrogel Beads using Biocompatible Ionic Liquid. J. Mol. Catal. B Enzym. 2012, 75, 68-72. [CrossRef]

47. Anitha, T.; Kumar, S.P.; Kumar, S.K. Synthesis of Nano-sized Nhitosan Blended Polyvinyl Alcohol for the Removal of Eosin Yellow Dye from Aqueous Solution. J. Water Process Eng. 2016, 13, 127-136.

48. Sanyang, M.L.; Sapuan, S.M.; Jawaid, M.; Ishak, M.R.; Sahari, J. Effect of Sugar Palm-derived Cellulose Reinforcement on the Mechanical and Water Barrier Properties of Sugar Palm Starch Biocomposite Films. BioResources 2016, 11, 4134-4145. [CrossRef]

49. Abitbol, T.; Rivkin, A.; Cao, Y.; Nevo, Y.; Abraham, E.; Ben-Shalom, T.; Lapidot, S.; Shoseyov, O. Nanocellulose, A tiny Fiber with Huge Applications. Curr. Opin. Biotechnol. 2016, 39, 76-88. [CrossRef] [PubMed]

50. Díez-Pascual, A.M. Synthesis and Applications of Biopolymer Composites. Int. J. Mol. Sci. 2019, 20, 2321. [CrossRef]

51. Adewuyi, A. Chemically Modified Biosorbents and their Role in the Removal of Emerging Pharmaceutical Waste in the Water System. Water 2020, 12, 1551. [CrossRef]

52. Wan Ngah, W.S.; Teong, L.C.; Wong, C.S.; Hanafiah, M.A.K.M. Preparation and Characterization of Chitosan-zeolite Composites. J. Appl. Polym. Sci. 2012, 125, 2417-2425. [CrossRef]

53. Xie, J.; Li, C.; Chi, L.; Wu, D. Chitosan Modified Zeolite as a Versatile Adsorbent for the Removal of Different Pollutants from Water. Fuel 2013, 103, 480-485. [CrossRef]

54. Metin, A.Ü.; Çiftçi, H.; Alver, E. Efficient Removal of Acidic Dye using Low-cost Biocomposite Beads. Ind. Eng. Chem. Res. 2013, 52, 10569-10581. [CrossRef]

55. Li, H.; Huang, D. Microwave Preparation and Copper Ions Adsorption Properties of Crosslinked Chitosan/ZSM Molecular Sieve Composites. J. Appl. Polym. Sci. 2013, 129, 86-93. [CrossRef]

56. Wang, S.F.; Shen, L.; Zhang, W.D.; Tong, Y.-J. Preparation and Mechanical Properties of Chitosan/Carbon Nanotubes Composites. Biomacromolecules 2005, 6, 3067-3072. [CrossRef] [PubMed]

57. Salam, M.A.; Makki, M.S.I.; Abdelaal, M.Y.A. Preparation and Characterization of Multi-Walled Carbon Nanotubes/chitosan Nanocomposite and its Application for the Removal of Heavy Metals from Aqueous Solution. J. Alloys Compd. 2011, 509, 2582-2587. [CrossRef]

58. Kuilla, T.; Bhadra, S.; Yao, D.; Kim, N.H.; Bose, S.; Lee, J.H. Recent Advances in Graphene based Polymer Composites. Prog. Polym. Sci. 2010, 35, 1350-1375. [CrossRef]

59. Huyen, N.T.M.; Trang, P.T.T.; Dat, N.M.; Hieu, N.H. Synthesis of Chitosan/graphene Oxide Nanocomposites for Methylene Blue Adsorption. In AIP Conference Proceedings; AIP Publishing: Melville, NY, USA, 2017; Volume 1878, p. 020013.

60. Nakkeeran, E.; Varjani, S.J.; Dixit, V.; Kalaiselvi, A. Synthesis, Characterization and Application of Zinc Oxide Nanocomposite for Dye Removal from Textile Industrial Wastewater. Indian J. Exp. Biol. 2018, 56, 498-503.

61. Arafat, A.; Samad, S.A.; Huq, D.; Moniruzzaman, M.; Masum, S.M. Textile Dye Removal from Wastewater Effluents using Chitosan-ZnO Nanocomposite. J. Text. Sci. Eng. 2015, 5, 5-8.

62. Vignesh Kumar, T.H.; Sivasankar, V.; Fayoud, N.; Oualid, H.A.; Sundramoorthy, A.K. Synthesis and Characterization of Coral-like Hierarchical MgO Incorporated Fly Ash Composite for the Effective Adsorption of Azo Dye from Aqueous Solution. Appl. Surf. Sci. 2018, 449, 719-728. [CrossRef]

63. Nga, N.K.; Hong, P.T.T.; Lam, T.D.; Huy, T.Q. A Facile Synthesis of Nanostructured Magnesium Oxide Particles for Enhanced Adsorption Performance in Reactive Blue 19 Removal. J. Colloid Interface Sci. 2013, 398, 210-216. [CrossRef] [PubMed]

64. Nga, N.K.; Thuy Chau, N.T.; Viet, P.H. Preparation and Characterization of a Chitosan/MgO Composite for the Effective Removal of Reactive Blue 19 dye from Aqueous Solution. J. Sci. Adv. Mater. Devices 2020, 5, 65-72. [CrossRef]

65. Song, Z.; Hu, Y.; Qi, L.; Xu, T.; Yang, Y.; Xu, Z.; Lai, X.; Wang, X.; Zhang, D.; Li, S. An Effective and Recyclable Deproteinization Method for Polysaccharide from Oyster by Magnetic Chitosan Microspheres. Carbohydr. Polym. 2018, 195, 558-565. [CrossRef] [PubMed]

66. Wang, N.; Xu, Z.; Xu, W.; Xu, J.; Chen, Y.; Zhang, M. Comparison of Coagulation and Magnetic Chitosan Nanoparticle Adsorption on the 2020, Removals of Organic Compound and Coexisting Humic Acid: A Case Study with Salicylic Acid. Chem. Eng. J. 2018, 347, 514-524. [CrossRef]

67. Zhu, H.Y.; Jiang, R.; Xiao, L.; Li, W. A Novel Magnetically Separable $\gamma-\mathrm{Fe}_{2} \mathrm{O}_{3}$ /crosslinked Chitosan Adsorbent: Preparation, Characterization and Adsorption Application for Removal of Hazardous Azo Dye. J. Hazard. Mater. 2010, 179, 251-257. [CrossRef]

68. Azari, A.; Noorisepehr, M.; Dehganifard, E.; Karimyan, K.; Hashemi, S.Y.; Kalhori, E.M.; Norouzi, R.; Agarwal, S.; Gupta, V.K. Experimental Design, Modeling and Mechanism of Cationic Dyes Biosorption on to Magnetic Chitosan-lutaraldehyde Composite. Int. J. Biol. Macromol. 2019, 131, 633-645. [CrossRef]

69. Sun, X.; Peng, B.; Ji, Y.; Chen, L.; Li, D. Chitosan(chitin)/cellulose Composite Biosorbents Prepared using Ionic Liquid for Heavy Metal Ions Adsorption. AIChE J. 2009, 55, 2062-2069. [CrossRef] 
70. Agarwal, A.; Vaishali, A. Chitosan Based Adsorbent: A Remedy to Handle Industrial Waste Water. Int. J. Eng. Sci. 2017, 6, 34-49.

71. Li, X.; Li, Y.; Zhang, S.; Ye, Z. Preparation and Characterization of New Foam Adsorbents of Poly(vinyl alcohol)/chitosan Composites and their Removal for Dye and Heavy Metal from Aqueous Solution. Chem. Eng. J. 2012, 183, 88-97. [CrossRef]

72. Hassan, H.; Salama, A.; El-ziaty, A.K.; El-Sakhawy, M. New chitosan/silica/zinc Oxide Nanocomposite as Adsorbent for Dye Removal. Int. J. Biol. Macromol. 2019, 131, 520-526. [CrossRef] [PubMed]

73. Li, J.; Jiang, B.; Liu, Y.; Qiu, C.; Hu, J.; Qian, G.; Guo, W.; Ngo, H.H. Preparation and Adsorption Properties of Magnetic Chitosan Composite Adsorbent for $\mathrm{Cu}^{2+}$ Removal. J. Clean. Prod. 2017, 158, 51-58. [CrossRef]

74. Kausar, A.; Naeem, K.; Tariq, M.; Nazli, Z.I.H.; Bhatti, H.N.; Jubeen, F.; Nazir, A.; Iqbal, M. Preparation and Characterization of Chitosan/clay Composite for Direct Rose FRN Dye Removal from Aqueous Media: Comparison of Linear and Non-linear Regression Methods. J. Mater. Res. Technol. 2019, 8, 1161-1174. [CrossRef]

75. Dotto, G.L.; Rodrigues, F.K.; Tanabe, E.H.; Fröhlich, R.; Bertuol, D.A.; Martins, T.R.; Foletto, E.L. Development of Chitosan/bentonite Hybrid Composite to Remove Hazardous Anionic and Cationic Dyes from Colored Effluents. J. Environ. Chem. Eng. 2016, 4, 3230-3239. [CrossRef]

76. Muinde, V.M.; Onyari, J.M.; Wamalwa, B.; Wabomba, J.N. Adsorption of Malachite Green Dye from Aqueous Solutions using Mesoporous Chitosan-zinc oxide Composite Material. Environ. Chem. Ecotoxicol. 2020, 2, 115-125. [CrossRef]

77. Travlou, N.A.; Kyzas, G.Z.; Lazaridis, N.K.; Deliyanni, E.A. Graphite oxide/chitosan Composite for Reactive Dye Removal. Chem. Eng. J. 2013, 217, 256-265. [CrossRef]

78. Coura, J.C.; Profeti, D.; Profeti, L.P.R. Eco-friendly Chitosan/quartzite Composite as Adsorbent for Dye Removal. Mater. Chem. Phys. 2020, 256, 123711. [CrossRef]

79. Abbasi, M.; Habibi, M.M. Optimization and Characterization of Direct Blue 71 Removal using Nanocomposite of ChitosanMWCNTs: Central Composite Design Modeling. J. Taiwan Inst. Chem. Eng. 2016, 62, 112-121. [CrossRef]

80. Wang, Y.; Wang, H.; Peng, H.; Wang, Z.; Wu, J.; Liu, Z. Dye Adsorption from Aqueous Solution by Cellulose/chitosan Composite: Equilibrium, Kinetics, and Thermodynamics. Fibers Polym. 2018, 19, 340-349. [CrossRef]

81. Marrakchi, F.; Hameed, B.H.; Hummadi, E.H. Mesoporous Biohybrid Epichlorohydrin Crosslinked Chitosan/carbon-clay Adsorbent for Effective Cationic and Anionic Dyes Adsorption. Int. J. Biol. Macromol. 2020, 163, 1079-1086. [CrossRef] [PubMed]

82. Fatombi, J.K.; Idohou, E.A.; Osseni, S.A.; Agani, I.; Neumeyer, D.; Verelst, M.; Mauricot, R.; Aminou, T. Adsorption of Indigo Carmine from Aqueous Solution by Chitosan and Chitosan/activated Carbon Composite: Kinetics, Isotherms and Thermodynamics Studies. Fibers Polym. 2019, 20, 1820-1832. [CrossRef]

83. Jawad, A.H.; Abdulhameed, A.S.; Malek, N.N.A.; Othman, Z.A. Statistical Optimization and Modeling for Color Removal and COD Reduction of Reactive Blue 19 Dye by Mesoporous Chitosan-epichlorohydrin/kaolin Clay Composite. Int. J. Biol. Macromol. 2020, 164, 4218-4230. [CrossRef]

84. Abdel Maksoud, M.I.A.; Elgarahy, A.M.; Farrell, C.; Al-Muhtaseb, A.H.; Rooney, D.W.; Osman, A.I. Insight on Water Remediation Application using Magnetic Nanomaterials and Biosorbents. Coord. Chem. Rev. 2020, 403, 213096. [CrossRef]

85. Rangabhashiyam, S.; Anu, N.; Selvaraju, N. Sequestration of Dye from Textile Industry Wastewater using Agricultural Waste Products as Adsorbents. J. Environ. Chem. Eng. 2013, 1, 629-641. [CrossRef]

86. Sadeek, S.A.; Negm, N.A.; Hefni, H.H.H.; Abdel Wahab, M.M. Metal Adsorption by Agricultural Biosorbents: Adsorption Isotherm, Kinetic and Biosorbents Chemical Structures. Int. J. Biol. Macromol. 2015, 81, 400-409. [CrossRef] [PubMed]

87. Sargin, I.; Arslan, G.; Kaya, M. Production of Magnetic Chitinous Microcages from Ephippia of Zooplankton Daphnia Longispina and Heavy Metal Removal Studies. Carbohydr. Polym. 2019, 207, 200-210. [CrossRef]

88. Bahrudin, N.N.; Nawi, M.A.; Sabar, S. Immobilized Chitosan-montmorillonite Composite Adsorbent and its Photocatalytic Regeneration for the Removal of Methyl Orange. React. Kinet. Mech. Catal. 2019, 126, 1135-1153. [CrossRef]

89. Kamal, M.A.; Bibi, S.; Bokhari, S.W.; Siddique, A.H.; Yasin, T. Synthesis and Adsorptive Characteristics of Novel Chitosan/graphene oxide Nanocomposite for Dye Uptake. React. Funct. Polym. 2017, 110, 21-29. [CrossRef]

90. Idohou, E.A.; Fatombi, J.K.; Osseni, S.A.; Agani, I.; Neumeyer, D.; Verelst, M.; Mauricot, R.; Aminou, T. Preparation of Activated Carbon/chitosan/carica Papaya Seeds Composite for Efficient Adsorption of Cationic Dye from Aqueous Solution. Surf. Interfaces 2020, 21, 178-183. [CrossRef]

91. Sadeghi-Kiakhani, M.; Arami, M.; Gharanjig, K. Dye Removal from Colored-textile Wastewater using Chitosan-PPI Dendrimer Hybrid as a Biopolymer: Optimization, Kinetic, and Isotherm Studies. J. Appl. Polym. Sci. 2013, 127, 2607-2619. [CrossRef]

92. Fomina, M.; Gadd, G.M. Biosorption: Current Perspectives on Concept, Definition and Application. Bioresour. Technol. 2014, 160, 3-14. [CrossRef]

93. Ahmad, T.; Danish, M. Prospects of Banana Waste Utilization in Wastewater Treatment: A Review. J. Environ. Manag. 2018, 206, 330-348. [CrossRef] [PubMed]

94. Michalak, I.; Chojnacka, K.; Witek-Krowiak, A. State of the Art for the Biosorption Process-A Review. Appl. Biochem. Biotechnol. 2013, 170, 1389-1416. [CrossRef]

95. Joseph, L.; Jun, B.M.; Flora, J.R.V.; Park, C.M.; Yoon, Y. Removal of Heavy Metals from Water Sources in the Developing World using Low-cost Materials: A Review. Chemosphere 2019, 229, 142-159. [CrossRef] [PubMed]

96. Nešić, A.R.; Veličković, S.J.; Antonović, D.G. Modification of Chitosan by Zeolite A and Adsorption of Bezactive Orange 16 from Aqueous Solution. Compos. Part B Eng. 2013, 53, 145-151. [CrossRef] 
97. Jabar, J.M.; Odusote, Y.A.; Alabi, K.A.; Ahmed, I.B. Kinetics and Mechanisms of Congo-red Dye Removal from Aqueous Solution using Activated Moringa Oleifera Seed Coat as Adsorbent. Appl. Water Sci. 2020, 10, 136. [CrossRef]

98. Simonin, J.P. On the Comparison of Pseudo-first order and Pseudo-second Order Rate Laws in the Modeling of Adsorption Kinetics. Chem. Eng. J. 2016, 300, 254-263. [CrossRef]

99. Rangabhashiyam, S.; Balasubramanian, P. Characteristics, Performances, Equilibrium and Kinetic Modeling Aspects of Heavy Metal Removal using Algae. Bioresour. Technol. Rep. 2019, 5, 261-279. [CrossRef]

100. Salehi, R.; Arami, M.; Mahmoodi, N.M.; Bahrami, H.; Khorramfar, S. Novel Biocompatible Composite (Chitosan-zinc oxide nanoparticle): Preparation, Characterization and Dye Adsorption Properties. Colloids Surf. B Biointerfaces 2010, 8, 86-93. [CrossRef]

101. Liu, Q.; Yang, B.; Zhang, L.; Huang, R. Adsorption of an Anionic Azo Dye by Cross-linked Chitosan/bentonite Composite. Int. J. Biol. Macromol. 2015, 72, 1129-1135. [CrossRef]

102. Vidal, R.R.L.; Moraes, J.S. Removal of Organic Pollutants from Wastewater using Chitosan: A Literature Review. Int. J. Environ. Sci. Technol. 2019, 16, 1741-1754. [CrossRef]

103. Habiba, U.; Siddique, T.A.; Talebian, S.; Lee, J.J.L.; Salleh, A.; Ang, B.C.; Afifi, A.M. Effect of Deacetylation on Property of Electrospun Chitosan/PVA Nanofibrous Membrane and Removal of Methyl Orange, Fe(III) and Cr(VI) ions. Carbohydr. Polym. 2017, 177, 32-39. [CrossRef] [PubMed]

104. Liu, Y.; Zheng, Y.; Wang, A. Enhanced Adsorption of Methylene Blue from Aqueous Solution by Chitosan-g-poly (acrylic acid)/vermiculite Hydrogel Composites. J. Environ. Sci. 2010, 22, 486-493. [CrossRef]

105. Nguyen, N.T.; Nguyen, N.T.; Nguyen, V.A. In Situ Synthesis and Characterization of ZnO/chitosan Nanocomposite as an Adsorbent for Removal of Congo Red from Aqueous Solution. Adv. Polym. Technol. 2020, 2020, 3892694. [CrossRef]

106. Jawad, A.H.; Abdulhameed, A.S. Mesoporous Iraqi Red Kaolin Clay as an Efficient Adsorbent for Methylene Blue Dye: Adsorption Kinetic, Isotherm and Mechanism Study. Surf. Interfaces 2020, 18, 71-76. [CrossRef]

107. Shazwani, N.; Mubarak, A.; Jawad, A.H.; Nawawi, W.I. Equilibrium, Kinetic and Thermodynamic Studies of Reactive Red 120 Dye Adsorption by Chitosan Beads from Aqueous Solution. Energy Ecol. Environ. 2017, 2, 85-93.

108. Jawad, A.H.; Shazwani, N.; Mubarak, A.; Sabar, S. Adsorption and Mechanism Study for Reactive Red 120 Dye Removal by Cross-linked Chitosan-epichlorohydrin Biobeads. Compos. Part B Eng. 2019, 75, 415-418. [CrossRef]

109. Hussain, S.; Kamran, M.; Khan, S.A.; Shaheen, K.; Shah, Z.; Suo, H.; Khan, Q.; Shah, A.B.; Rehman, W.U.; Al-Ghamdi, Y.O.; et al. Adsorption, Kinetics and Thermodynamics Studies of Methyl Orange Dye Sequestration through Chitosan Composites Films. Int. J. Biol. Macromol. 2021, 168, 383-394. [CrossRef] [PubMed]

110. Madala, S.; Kumar, S.; Vudagandla, S. Equilibrium, Kinetics and Thermodynamics of Cadmium (II) Biosorption on to Composite Chitosan Bosorbent. Arab. J. Chem. 2013, 75, 543-550.

111. Erenturk, S.A.; Kaygun, A.K. Removal of 226Ra from Aqueous Media and its Thermodynamics and Kinetics. J. Radioanal. Nucl. Chem. 2017, 311, 1227-1233. [CrossRef]

112. Tzereme, A.; Christodoulou, E.; Kyzas, G.Z.; Kostoglou, M.; Bikiaris, D.N.; Lambropoulou, D.A. Chitosan Grafted Adsorbents for Diclofenac Pharmaceutical Compound Removal from Single-component Aqueous Solutions and Mixtures. Polymers 2019, 11, 497. [CrossRef] 